\title{
Phytophagy in a Polypedilum (Diptera: Chironomidae) species new to Australia and Japan: taxonomy and expanded Asian distribution
}

\author{
Hongqu Tang ${ }^{1}$ (D) and Peter S Cranston ${ }^{2 *}$ (D) \\ ${ }^{1}$ Institute of Groundwater and Earth Science, Jinan University, Guangzhou 510632, China. \\ ${ }^{2}$ Evolution \& Ecology, Australian National University, Canberra, ACT 0200, Australia.
}

\begin{abstract}
Polypedilum johannseni Sublette \& Sublette (= Chironomus (Polypedilum) anticus Johannsen), described from Indonesia, is recorded from Australia, where larvae are newly reported to feed on species of the aquatic fern Azolla Lam. (Salviniaceae). We extend the Australian distribution for the species that was reported previously as Polypedilum 'nr seorsus' from northern Australia. Review of the species in Asia shows previously known presence in Singapore as Polypedilum anticus and in Thailand and the Philippines, where the larva was reported to feed on Azolla. In China, Polypedilum johannseni is reported from a diverse range of aquatic host plants, including Azolla. We also newly report the species from Japan, where larvae feed on hybrid Azolla cristata $\times$ Azolla filiculoides and Trapa japonica Flerow (Lythraceae). We review the taxonomy, provide new illustrations, record and map the wider distribution and comment on morphological variation. Here, we also redescribe the Australian Polypedilum seorsus (Skuse) with which P. johannseni has been confused, and from China, we redescribe Polypedilum tigrinum Hashimoto, the larva of which is a proven aquatic phytophage that co-occurs with several species of Polypedilum, including P. johannseni.
\end{abstract}

\section{Key words Azolla, China, phytophagy, Singapore.}

\section{INTRODUCTION}

A diverse assemblage of non-biting midges are phytophagous (herbivorous) as larvae, eating submerged aquatic plants (Pinder 1986; Earle et al. 2013). Although summaries have been published (e.g. Armitage et al. 1995; Tóth et al. 2012; and references therein), commonly larval diet has been deduced from only limited observations. Insufficient experimental manipulations have been made to verify the role of plant feeding or breadth of host plants utilised (Stagliano et al. 1998; Stratman et al. 2013). Larvae of the diverse and speciose genus Polypedilum Kieffer include species associated with aquatic macrophytes including in North America (e.g. Balci \& Kennedy 2003; Harms et al. 2011), but proof of identity and phytophagy is infrequent. Some species are pests of crops of edible and ornamental aquatic plants, and these, and others verified as phytophages, have been considered for biological control of nuisance aquatic 'weeds' (e.g. Hashimoto 1985; Maschwitz \& Cook 2000; Earle et al. 2013; Andersen et al. 2015).

Polypedilum is a worldwide genus that includes at least 440 described species (Andersen et al. 2015) with an internal classification system of subgenera that is unstable and not fully validated from phylogeny (e.g. Sæther \& Oyewo 2008; Kawai et al. 2012; Cranston et al. 2016). Many descriptions are of single species based on the adult male alone, but synthesis and reconciliation with immature stages has progressed, e.g. by Sæther $e t$ al. (2010), Epler et al. (2013) and Ekrem et al. (2017). In Asia, studies of adults predominate (e.g. Niitsuma 1991; Kawai et al. 1998; Zhang et al. 2016), but immature stages are included in Tang et al. (2014) and Cranston et al. (2016), amongst others. A provisional illustrated key to immature stages of Australian Polypedilum (Cranston 1996, 2000a) needs updating following new descriptions (Cranston 2000b) and ongoing updating of coded taxa with formal names (e.g. Tang et al. 2014; Cranston 2018, 2019; Cranston \& Tang 2018).

Here, we reassess the identity of a species of Australian Polypedilum termed 'nr seorsus', previously conflated with Polypedilum seorsus (Skuse) by Cranston (1996). This review was stimulated by the discovery in Australia of larvae feeding on Azolla Lam, namely, Azolla pinnata R. Br., an aquatic fern under consideration for biocontrol (M. Purcell \& B. Brown, CSIRO, Brisbane, unpublished information). This necessitated study of reared material from Australia and Asia, survey of a widely scattered literature, much in obscure literature and consideration of possible misidentifications. The results reveal a species new to Australia, Polypedilum johannseni Sublette \& Sublette, described from Indonesia, now with a substantially wider distribution including China and newly from Japan. Reared series of specimens or from male swarms reveal morphological variation, including even in diagnostic pigmentation and mensural features: this will require investigation with molecular data. We consider two species that have been confused with $P$. johannseni, one Australian (P. seorsus) and the other Asian (Polypedilum tigrinum Hashimoto), and we redescribe and illustrate these taxa to allow differentiation.

*pscranston@gmail.com 


\section{MATERIALS AND METHODS}

General collection methods included kick netting and disturbance of marginal aquatic habitats for larvae and pupae and sweeping and light trapping for adults. Pupae, exuviae and drowned pharate adults were sought by exposing drift nets with a $300 \mu \mathrm{m}$ mesh to intersect flowing water surfaces. Collections usually were field sorted with a dissector microscope and life history associations, and live larvae for rearing were sought. Communal and individual rearings of larvae from Azolla were made by Bradley Brown from Australian field collections, to verify larval feeding on Azolla. Specimens were mounted on slides in Euparal using standard procedures (Cranston 1996, 2000a). Both sexes of adults plus larvae were imaged by Yuchen Ang using the Visionary Digital ${ }^{\mathrm{TM}}$ Plus Lab System (CF4P3 magnification) (see Ang et al. 2013). Ink drawings made by hand using a drawing tube were manipulated using Adobe ${ }^{\circledR}$ Photoshop $^{\mathrm{TM}}$.

\section{Morphology}

Morphological terminology follows Sæther (1980), Cranston $(1995,2013)$ and Cranston et al. (1989). However, an alternate to 'humeral setae' of the adult thorax (Sæther 1980) was introduced by Maschwitz and Cook (2000) for North American Polypedilum, namely, 'scutal fossal setae'. This term was retained from thesis to eventual publication, although Sæther (2001) in a review stated that the Maschwitz and Cook (2000) study 'follows the morphological terminology of Sæther (1980)'; this was not correct regarding the anterolateral thorax. A fossa is a pit or depression, whereas humeral refers to the 'shoulder' - neither is particularly applicable. According to Google Scholar ${ }^{\mathrm{TM}}$, fossal (setae) is used almost exclusively in Culicidae but in Chironomidae only by Sæther et al. (2010). In contrast, humeral is used widely and always in Acari for positionally homologous setae, and we retain this term.

Another terminological issue concerns the pupal abdomen in which the pattern of spines and spinules (armament) provides valuable evidence of species identity. In Polypedilum pupae (and many other taxa), diagnostic transverse bands of anteriorly directed 'points' lie on either the posterior tergite or the intersegmental membrane, termed a conjunctive. Although definition of the boundary of the conjunctive in relation to the posterior termination of the tergite is unclear, as M. Spies (unpublished observation) has observed 'conjunctival' structures are located clearly and fully posterior to the posterior ends of the respective tergite's lateral muscle marks and apodemes and on IV posterior to the level of the sternal vortex/pedes spurii A. Most importantly, the spinules ('points') in the most posterior transverse band, typically treated as being conjunctival, are directed to the anterior (like the hook row on TII) in contrast to all other anterior armament spinules that are directed posteriorly. We use the term conjunctive, numbered from the tergite anterior to it - thus, the hook row is on conjunctive II.

\section{Abbreviations}

Abbreviations of morphological characters principally used Tables S1 and S2. Lengths are in microns $(\mu \mathrm{m})$ unless stated as mm. Adult, unless stated. Ant1-12, 13, combined length of antennal flagellomeres 1-12, $13\left({ }^{\lambda}\right)$; A.R., antennal ratio = (adults): length of terminal flagellomere divided by combined length of preceding flagellomeres $(\widehat{O} 1-12 ;$; $1-4)$; B.l., total body length in $\mathrm{mm} ; B V$, 'Beinverhältnis': length of femur, tibia plus first tarsomere/combined length of tarsomeres 2-5; Clyp, clypeus setae (count); $D c$, dorsocentral setae (count); $L$, larva; $L e$, larval

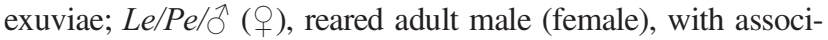
ated larval and pupal exuviae; $M V$, molecular voucher; $n$, number of specimens measured; $P_{1-3}, \operatorname{leg}(\mathrm{s})(1=$ fore; $2=$ mid; $3=$ hind leg); Palp, palpomere lengths; $P(e)$, pupa (exuviae); $P \hat{O}(+)$, pharate male (female) within pupa; Scts, scutellar setae; $S V$, 'Schenkel-Schiene-Verhältnis' = combined length of femur and tibia/length of first tarsal segment; V.R., vein ratio $=$ length of $\mathrm{Cu} /$ length of $\mathrm{M}$; $W l$, wing length in $\mathrm{mm}$ (arculus to apex).

Geographical terms: ACT, Australian Capital Territory; C., City; Co., County; Distr., District; E, east; L, Lake; Mt, Mountain; Mun., Municipality; NNR, National Nature Reserve; NFP, National Forest Park; NSW, New South Wales (Australia); N, north; NT, Northern Territory (Australia); Pref., Prefecture; Prov., Province; Qld, Queensland (Australia); R., River; Res., Reservoir; S, South; SA, South Australia; W, west.

Distributional data are organised from North to South in both hemispheres.

Specimens are conserved in the Australian National Insect Collection CSIRO, Canberra, Australia (ANIC), The Natural History Museum, London, U.K. (BMNH), The Institute of Groundwater and Earth Science, Jinan University, Guangzhou, China (EJNU), and National Museum of Victoria, Melbourne, Victoria, Australia (NMV).

\section{TAXONOMY}

\section{Polypedilum johannseni Sublette \& Sublette, 1973 (Figs I-4)}

Chironomus (Polypedilum) anticus Johannsen 1932: 521.

Propedilum anticum (Johannsen); pupa Lenz 1937: 271 [genus Propedilum synonymised with Polypedilum by Townes 1945].

Polypedilum anticum (Johannsen); Karunakaran 1969, Takara 1981.

Polypedilum johannseni Sublette \& Sublette 1973: 407, replacement name for Chironomus anticus Johannsen, preoccupied when in Chironomus by Chironomus anticus Walker 1848.

Polypedilum 'nr seorsus' (Skuse), Cranston 1996, 2000a.

nec Chironomus seorsus Skuse 1889: 241, see below.

\section{Material examined}

Holotype. J ' Chironomus (Polypedilum) anticus, slide mounted, INDONESIA: West Java, Buitenzorg $[=$ Bogor $]$ (coll. Thienemann Sunda Exped) (BMNH); Pe, as $\widehat{\partial}$, slide mounted (ZSM). 

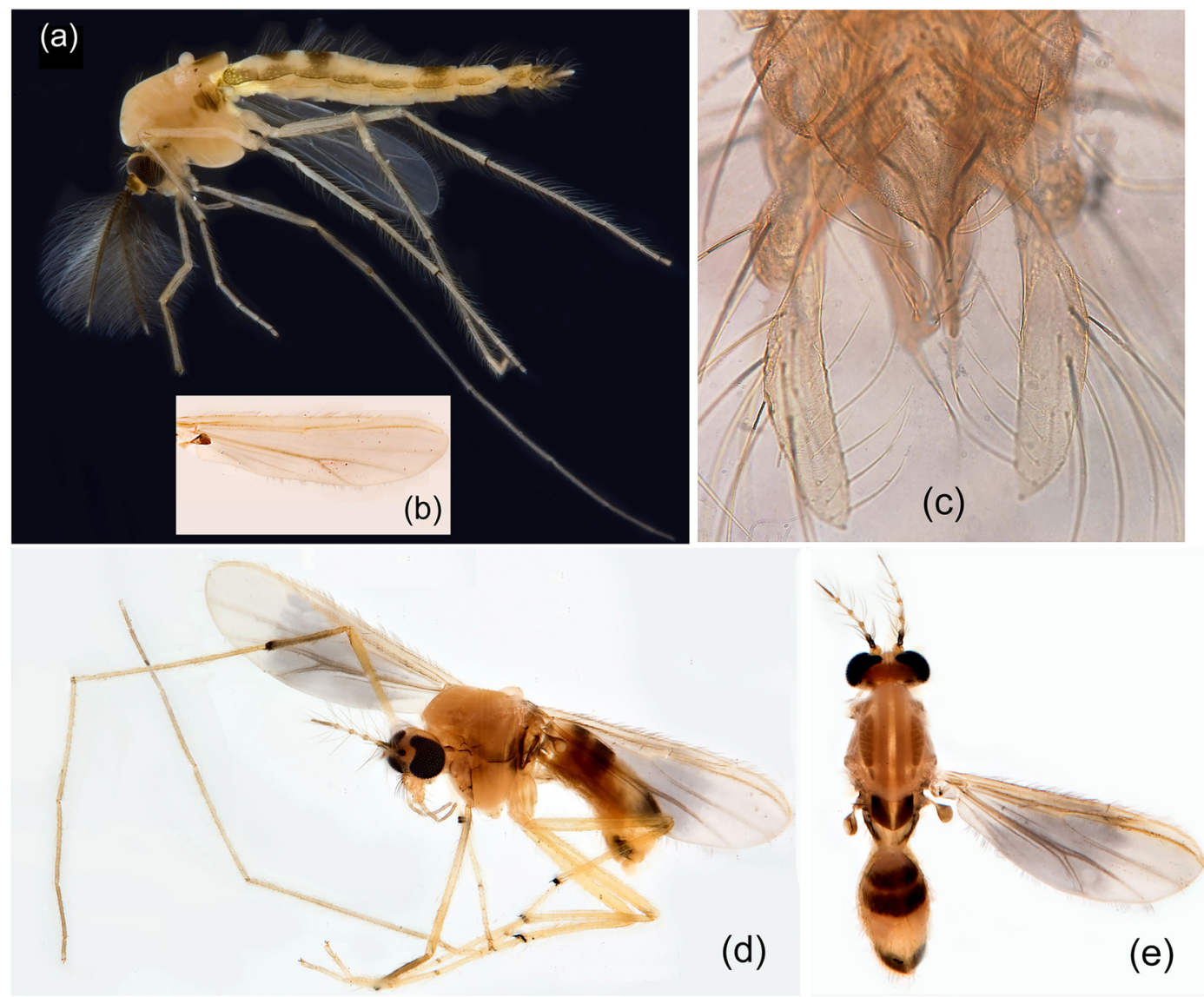

Fig. 1. Polypedilum johannseni Sublette \& Sublette. Adults: (a) male habitus, insert (b) wing, (c) hypopygium, (d) female habitus lateral, (e) dorsal. (a-b, d-e) Singapore, Yuchen Ang; (c) China: Canton Pearl River Park.

Other material. (Australia collected by Cranston unless stated, deposited ANIC; China collected by Tang unless stated, deposited EJNU).

AUSTRALIA: Northern Territory, 2 Le/Pe/ $\widehat{\jmath}, \mathrm{Le} / \mathrm{Pe} / q$, , $8 \hat{\circ}$, 4, 8Pe, Kakadu N.P., Nankeen Billabong, $12^{\circ} 27^{\prime}$ S $133^{\circ} 52^{\prime} \mathrm{E}$, 7.vi.1988; L, S Alligator R., Yellow Waters, 'ex-Nymphoides leaves', 12 ${ }^{\circ} 56^{\prime} \mathrm{S} 132^{\circ} 32^{\prime} \mathrm{E}$, 30.v.1988; đo '19 km N by E Mt Cahill', Baroalba Springs, 12 $50^{\prime} \mathrm{S}$ 132 $54^{\prime} \mathrm{E}, 13 . \mathrm{vi} .1973$ (Colless); 2Pe, Coronation Hill 'below BHP', 13³2'S 132 $30^{\circ}$ E, 25.v.1988; L, Litchfield N.P., Pethericks Thermal Pool, $13^{\circ}$ $07^{\prime} \mathrm{S} 130^{\circ} 39^{\prime} \mathrm{E}$, 6.viii.1990; L, Wongi Falls, $13^{\circ} 10^{\prime} \mathrm{S} 130^{\circ} 41^{\prime} \mathrm{E}$, 6.viii.1990. Queensland, 8 Pe, Proserpine, Brandy Ck. 20²1' 20"S 14943'15"E, 21-23.iii.1998; L, Tamborine Mt, Cedar

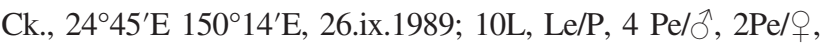
Brisbane, Sherwood Arboretum, 27 $31^{\circ} 91^{\prime} \mathrm{S} 152^{\circ} 58.46^{\prime}$ E.iiiiv.2019 (Brown, CSIRO Brisbane), reared 'ex-Azolla pinnata'. New South Wales, 2Pe, Cocoparra N.P., Woolshed Ck., 3405' S 149 ${ }^{\circ} 3^{\prime}$ E, 31.x.1993. Victoria, 8 km N Benalla, Broken River, along Midland Hwy, 36²8.42'S 145'56.52'E, ii.2019 (Brown, CSIRO Brisbane). Western Australia, ${ }^{\top}, 4 \mathrm{k}$ w. King Cascade, CALM site \#28/3, 15³8'S $135^{\circ} 15^{\prime} \mathrm{E}, 12-16$.vi.1988 (Weir).

SINGAPORE: $2{ }^{\lambda}$, + ., Upper Seletar Reservoir, $1^{\circ} 24^{\prime} \mathrm{N} 103^{\circ}$ 48'E, 2009 (Yuchen Ang) (ANIC).

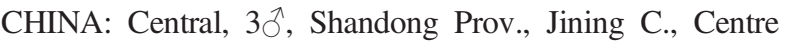
Distr., Jinghang Canal, Huotouwan Bay, $35^{\circ} 26^{\prime} \mathrm{N} 116^{\circ} 30^{\prime} \mathrm{E}$, 01-04.x.2018 (1ふ, ANIC).
South, §̊, Guangdong Prov., Guangzhou C., Zengcheng Dist., Lan Stream, $23^{\circ} 21^{\prime} \mathrm{N} 113^{\circ} 58^{\prime} \mathrm{E}, 12 . i v .2018$ (ANIC); 3P $\widehat{\jmath}$, Huangpu Dist., Jinkeng Res., 23ำ $15^{\prime} \mathrm{N} 113^{\circ} 31^{\prime} \mathrm{E}$, 14.xii.2016 (ANIC); 3 Pe/ð̄, ふ̄, Tianhe Dist., Pearl Park, $23^{\circ} 07^{\prime} \mathrm{N} 113^{\circ} 20^{\prime}$ E, 14.v.2018 (1ठ̄, ANIC); Le/Pe/ô, ô, o , Ningcheng Park, $22^{\circ}$

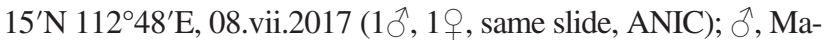
cau SAR, a pond of St. Lazarus, near Taipa Houses Museum, $22^{\circ}$ 09'N 113³4'E, 20.x.2014; §̋, Hainan Prov., Tunchang Co., Nanlyu T., Zhenghong Reservoir, 19² $14^{\prime} \mathrm{N} 110^{\circ} 08^{\prime} \mathrm{E}, 07$. ii.2015. South-west, 2ð, Yunnan Prov., Nujiang Pref., Fugong Co., Pihe T., pond nr Laomudeng Christian Church, $26^{\circ} 33^{\prime} \mathrm{N}$ 98 55'E, 14.x.2017; 2ð̄, Yunnan Prov., Xisuangbannan Pref., Jinghong C., Menglun T., Botanical Garden, $21^{\circ} 56^{\prime} \mathrm{N} 101^{\circ} 15^{\prime} \mathrm{E}$, 22.iii.2019; §̊, Mengla Co., Wangtianshu Scenic Spot, $21^{\circ} 37^{\prime} \mathrm{N}$

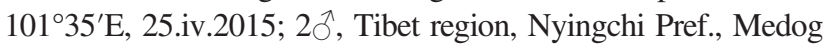
Co., unnamed pond, $29^{\circ} 20^{\prime} \mathrm{N} 95^{\circ} 20^{\prime} \mathrm{E}, 12$.vii. 2014.

Other material examined (alcohol specimens). CHINA: Southeast, 11Pe/ , Fujian Prov., Sanming C., Jiangle Co., a pond in Longqishan NNR, $26^{\circ} 31^{\prime} \mathrm{N} 117^{\circ} 18^{\prime}$, 15.xi.2012.

South, 5^, 2 , , Guangdong Prov., Shantou C., Nan'ao Co., Marine Field Station of Shantou University, $23^{\circ} 29^{\prime} \mathrm{N} 117^{\circ} 07^{\prime}$ E; 21.ix.2018; 10ふै, 2ㅇ, Guangdong Prov., Chaozhou C., Chaonan Distr., Jinxi Reservoir, $23^{\circ} 11^{\prime} \mathrm{N} 116^{\circ} 18^{\prime} \mathrm{E}, 15$. vi.2016; 今̄, 1Pe/q, Guangxi Prov., Guilin C., Qingshitan Reservoir, $25^{\circ} 32^{\prime} \mathrm{N} 110^{\circ} 14^{\prime} \mathrm{E}, 26$.viii. 2014 . 
South-west, 6ㅊ, 2ㅇ, Guizhou Prov., Chishui City, Lushi Town, $28^{\circ} 29^{\prime} \mathrm{N} 105^{\circ} 54^{\prime} \mathrm{E}$, 13.viii.2018 (Han, W. \& Gou, T.G.); $2 \widehat{\jmath}, 1$, , Sichuan Prov., Yibin City, Xingwen Co., Shihai Town, $28^{\circ} 10^{\prime} \mathrm{N} 105^{\circ} 08^{\prime} \mathrm{E}, 08-09 . v i i i .2018$ (Han, W. \& Gou, T.G.); 4ㅇ, Chongqing Mun., Qianjiang District, Qianjiang R., $29^{\circ} 31^{\prime} \mathrm{N}$ $108^{\circ} 44^{\prime} \mathrm{E}$ (Han, W. \& Gou, T.G); 6今̄, 5q, Fuling Distr., Wulingshan NFP, $29^{\circ} 31^{\prime} \mathrm{N} 107^{\circ} 32^{\prime} \mathrm{E}, 23$.viii.2018 (Han, W. \& Gou, T.G.); $2 \widehat{\jmath}, 3 q$, Jiulongpo District, Huayan T., Huayan

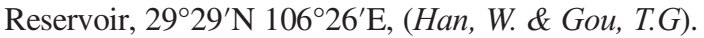

JAPAN: $2 \mathrm{P}+6 \mathrm{Pe}, 4 \mathrm{~L}$, Osaka, Sakai, Osaka Prefectural University, $\quad 34^{\circ} 32^{\prime} \mathrm{N} \quad 135^{\circ} 30^{\prime} \mathrm{E}, \quad 9 . x .2015, \quad$ ex-Azolla cristata $\times$ A. filiculoides hybrid (Yamamoto) (ANIC); 20+ $\delta^{\uparrow}+$, same data, except.x.2019 (some to EJNU).

\section{Diagnosis}

In Australia, $P$. johannseni is characterised in the male in wing features by the widely separated $\mathrm{R}_{1}$ and $\mathrm{R}_{4+5}$ with scant indication of vein $R_{2}+3$ and with $R_{4}+5$ meeting the costa at the extreme apex of the wing. The patterned abdomen (Fig. 1a), dark transverse band on the thoracic pleurae (although sometimes faint) and the genitalia with narrow parallel-sided anal point and long slender superior volsella arising from a relatively narrow base form a unique combination. The female wing has a broad medial dark band (Fig. 1d,e) but otherwise shares nongenitalic characteristics with the male. The dark foretibia, characteristic banded abdomen (Fig. 1e) and dark band on the thoracic pleurae (Fig. 1d) assist in characterisation. In the pupa, the strong armament of TII, as on TIII-VI, and the presence of a multiserial transverse spinule band only on conjunctive IV seems to be a unique combination. The larva is differentiated only with difficulty by the following combination of character states: mentum uneven with six pairs of lateral teeth evenly declining in size laterally yet all distinct (without reduced/retracted seventh), mandible with two inner teeth, each antennal segment successively shorter than preceding, with A. R. 1.1-1.4, and absence of Lauterborn organs. The mediandirected inner ventromental plate, antenna with consecutively shorter segments and narrow occipital margin assist in separation from several named and coded Polypedilum larvae keyed in Cranston (1996, 2000a).

Although this taxon was referred to as Polypedilum seorsus and 'nr seorsus' in Cranston (1996), the true P. seorsus, redescribed below, has plain wings in both sexes and lacks dark bands on thoracic pleurae and abdomen, the superior volsella of the male is shorter and more curved and pupal conjunctives III and IV both have transverse bands of spinules. Although the intensity of wing and body pigmentation varies in slide-mounted specimens of $P$. johannseni, evidently $P$. seorsus is a distinct, more temperate species.

In Asia, P. johannseni may be confused with Polypedilum tigrinum Hashimoto in the males that resemble each other by a somewhat similar colour pattern. This species is redescribed and illustrated in all stages below to allow recognition and differentiation. A difference is the microtrichiose adult wing that is shared with species in subgenus Pentapedilum Kieffer but on all other grounds should be placed in the nominate subgenus with $P$. johannseni and $P$. seorsus.

\section{Description}

Male $(\boldsymbol{n}=10+)$. Body length 2.6-3.6 mm, yellow with dark lateral vittae, lateral stripe on pleurae, postnotum, some of anterior femora and all of tibia and several abdominal terga (Fig. 1a). Wing (Fig. 1b) length 1.3-1.8 mm, slightly smoky, bare. Antenna with brown flagellomeres and dark, almost black, plume; flagellomere 1-12 lengths, 320-400, flagellomere 13, 530-750, AR 1.5-2.0. Frontal tubercles absent or weak. Head with 5-20 verticals + postorbitals near linearly aligned, 13-23 strong clypeals, palp segment 2-5 lengths, 30-55; 65-130; $60-145 ; 125-170$. Thorax with $2-7$ antepronotals, $7-14$ bilinear acrostichals, 2-4 isolated humerals, 9-13 unilinear dorsocentrals, 3-4 prealars, 4-6 unilinear scutellars. Legs with anterior tibia with basal and apical dark bands, other foreleg segments and mid- and hind legs pale, unmarked; leg ratios: $\mathrm{LR}_{1}$ 1.78-2.26, $\mathrm{BV}_{1}$ 1.37-1.53, $\mathrm{SV}_{1}$ 1.22-1.42; $\mathrm{LR}_{2}$ 0.54-0.63, $\mathrm{BV}_{2}$ 3.63-4.26, $\mathrm{SV}_{2}$ 3.41-3.97; $\mathrm{LR}_{3}$ 0.43-0.83, $\mathrm{BV}_{3}$ 2.572.87, $\mathrm{SV}_{3}$ 2.4-3.11; foretibial apex with well-developed triangular lobe tapering evenly to point (Fig. 2e), length 40, mid-leg with broad inner comb and narrower outer comb with spur, length 25; hind leg with broad inner comb, narrower outer comb with long spur, length 25 . Wing slightly smoky, nonmicrotrichiose, $\mathrm{R}_{2}+3$ essentially absent or slight trace running close to $R_{1}$ widely separated from $R_{4+5}$, running to end at apex of wing without costal extension, setation: $\mathrm{R}$ with 8-24, $\mathrm{R}_{1}$ with 9-23, R 4 + 5 with 14-30; 3-8 squamals; V.R. 1.10-1.26.

Genitalia (Figs 1c and 2a-d) with strong tergite IX bands surrounding paler median ovoid area, fading posteriorly towards base of anal point; 6-12 long median dorsal tergite IX setae; posterior tergite IX with 5-6 marginal setae and 4-5 setae around anal point base. Anal point (Figs $1 \mathrm{c}$ and $2 \mathrm{a}-\mathrm{c}$ ) arises from subposterior margin of tergite IX, dark at base then paler to apex, near parallel-sided in mid-section (5-8 wide), either tapering to pale slender (almost spine), 2 wide at apex, or slightly dilate apex; gently down-curved in lateral view. Superior volsella (Fig. 2a-d) arises from weakly microtrichiose, variably broadened base; extension slender (5-6 wide) throughout, rounded and slightly upcurved apically, 60-65 long, dorsally bearing pale fine seta, 75-85 long, located close to mid-volsella but between 40 and $60 \%$ of length. Inferior volsella microtrichiose except for bare subapical area, within which 7-8 dorso-medially orientated long and sometimes apically feathered setae arise; dilate apically especially in lateral view, with distinctive strong apical seta, 100-110 long. Gonocoxite bulbous, gonostylus 110-140 long, narrow at junction with gonocoxite incised (perhaps characteristically), broadened medially and tapering only slightly to rounded apex, microtrichiose throughout on both surfaces, with 5-6 mesally directed setae on inner margin, but with no dominant apical seta.

Female $(\boldsymbol{n}=7)$. Body length c $2.0-3.4 \mathrm{~mm}$, wing length 1.3-1.6 mm. Colour: basal and apical antennal segments dark, thoracic vittae more yellow-brown, postnotum and pleural strip 

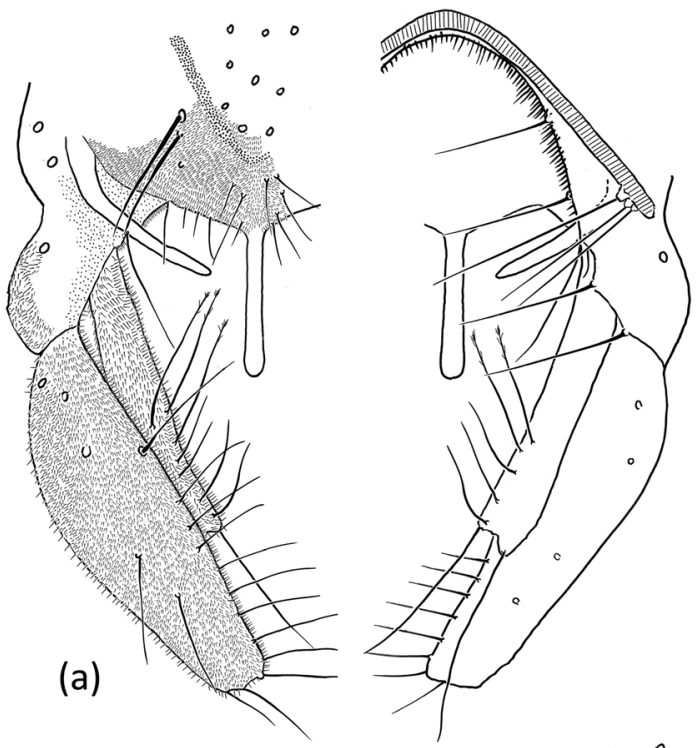

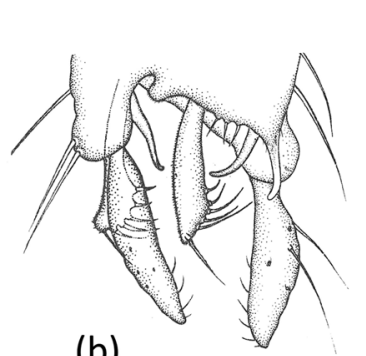

(b)

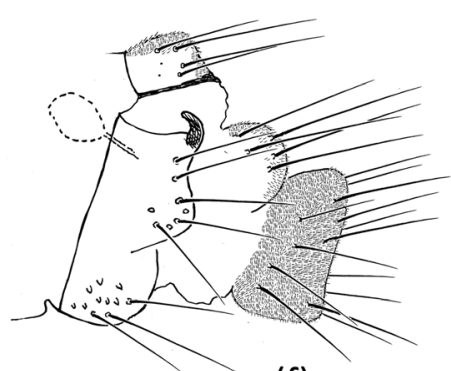

(f)

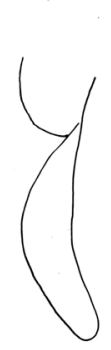

4

(c)<smiles>C1CCCC1</smiles>

(e)

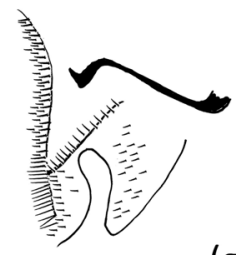

(g)

Fig. 2. Polypedilum johannseni Sublette \& Sublette. Adults: (a) hypopygium, schematic (left-side dorsal and right-side ventral/internal); (b) dorso-lateral hypopygium; (c) gonostylus, gonocoxite, anal point, superior volsella of holotype; (d) superior volsella; (e) anterior tibial spur, holotype; female genitalia (f) lateral, (g) lobes of gonapophysis VIII. (a, f, g) Australia, Qld, ex-azolla, (b) Johannsen (1932: Pl. LXXI, fig. 9), (d) Singapore.

strongly darkened; abdomen as in Figure 1d,e, with complete tergum I, posterior $80 \%$ terga 2, 3 and 6 dark, sterna pale except for brown genitalia. Flagellomeres (1-4): 106-150, 85-100, $85-110,170-190$, antennal ratio $0.53-0.66$. Head with 9-13 verticals + postorbitals linearly aligned, 10-27 strongly clustered clypeals, palps (2-5) 40-50, 70-90, 90-110, 140-200. Thorax with 2-5 antepronotals, 6-9 acrostichals, 2-5 humerals, 8-12 dorsocentrals, 3-4 prealars, 6-8 scutellars. Wing with broad transverse dark band (Fig. 1d,e), non-microtrichiose, weakly punctate, $R_{2+3}$ not distinguishable /absent, $R_{1}$ widely separated from $R_{4+5}$, ending at $2 / 3$ wing length, $R_{4+5}$, curved to end at apex of wing without costal extension; setation: $\mathrm{R}$ with $13-24$, $\mathrm{R}_{1}$ with 11-18, $\mathrm{R}_{4}+5$ with 21-38; 5-8 squamals; V.R. 1.11.2. Legs: anterior tibia with basal and apical dark bands, sometimes near merged, other segments and legs pale, unmarked; leg ratios: $\mathrm{LR}_{1} 1.87-2.28, \mathrm{BV}_{1} 1.48-1.60, \mathrm{SV}_{1} 1.26-1.42 ; \mathrm{LR}_{2}$ $0.50-0.58, \mathrm{BV}_{2}$ 3.64-4.27, $\mathrm{SV}_{2} 3.81-4.17 ; \mathrm{LR}_{3}$ 0.69-0.76, $\mathrm{BV}_{3} 2.68-2.87, \mathrm{SV}_{3} 2.92-3.05$. Genitalia (Fig. 2f,g) typical for Polypedilum. Notum 100-110 long bluntly rounded anteriorly, seminal capsules subovate 50-60 wide/high, with slightly sinuous ducts, dorsomesal lobe conventional-shaped with fewer microtrichia than in most congeners, ventrolateral lobe small, very weakly developed without brush-like setae including on inner margin and with few microtrichia; cerci $(80 \times 80)$ essentially quadrate, with squared-off posterior margin.

Pupa $(\boldsymbol{n}=10$ ) (Fig. 3a-f). Length $~ 3.5-4.8 \mathrm{~mm}$. Cephalothorax including antennal and wing sheaths outlined in brown, abdomen hyaline with indistinct apophyses and only comb darkened. Cephalothorax: frontal tubercles absent (Fig. 3c), pale frontal 
(a)

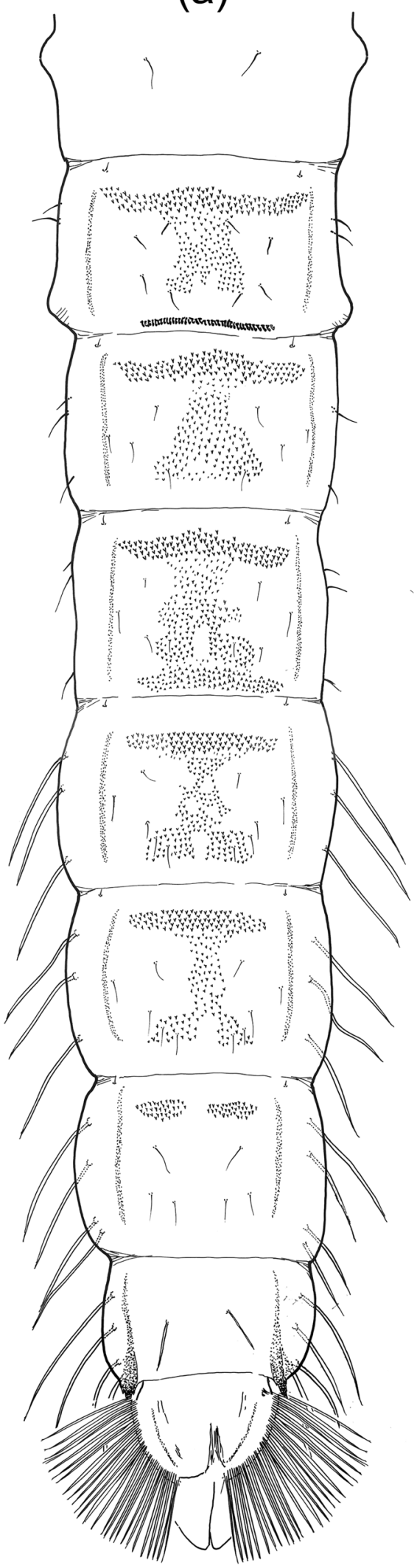

(b)
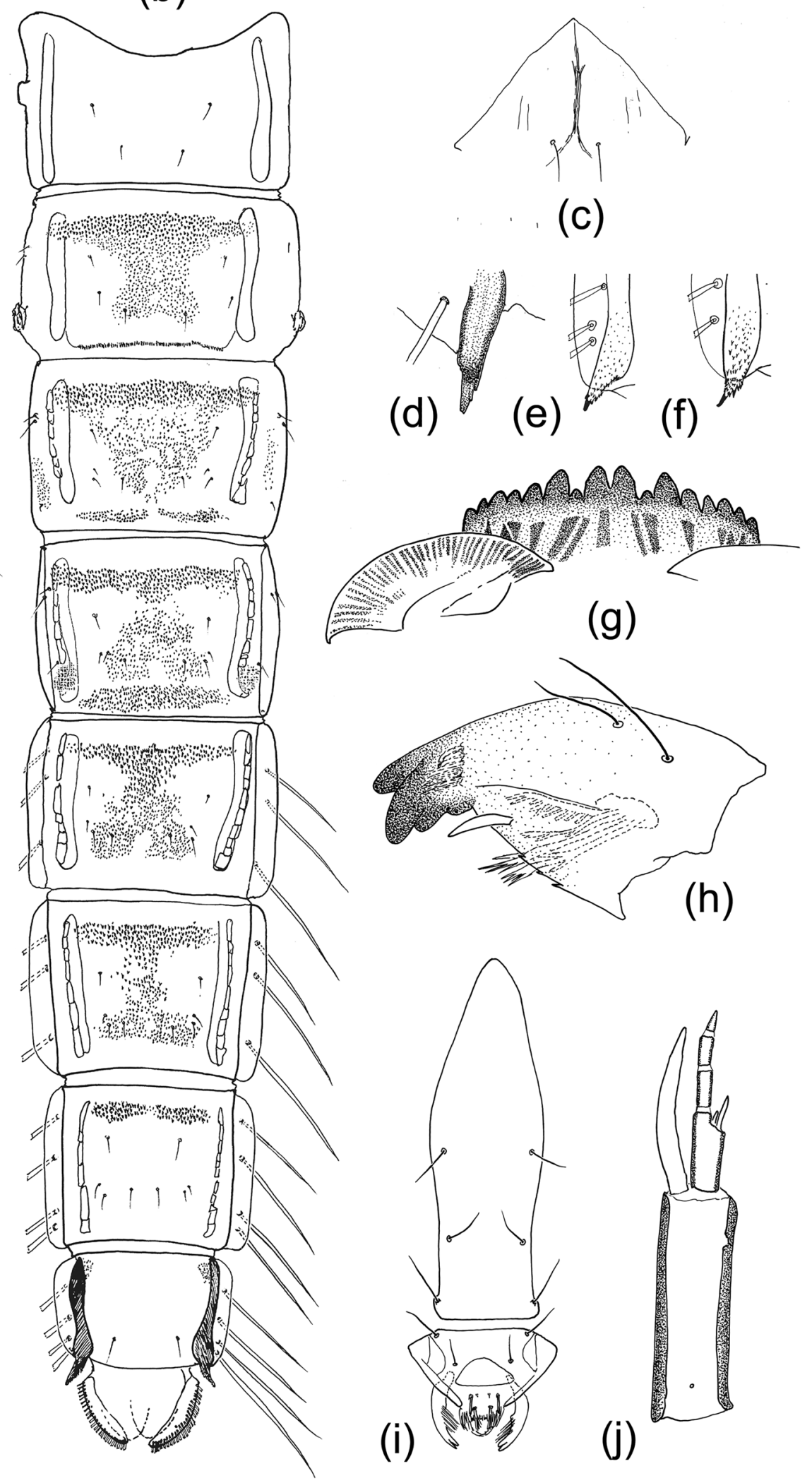

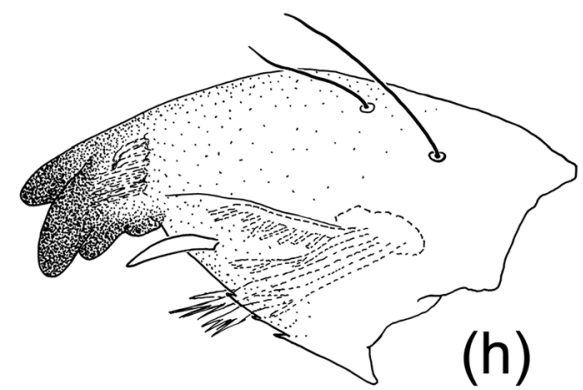

(h)

(d)

(e)

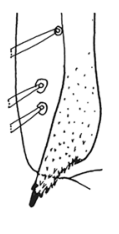

(f)
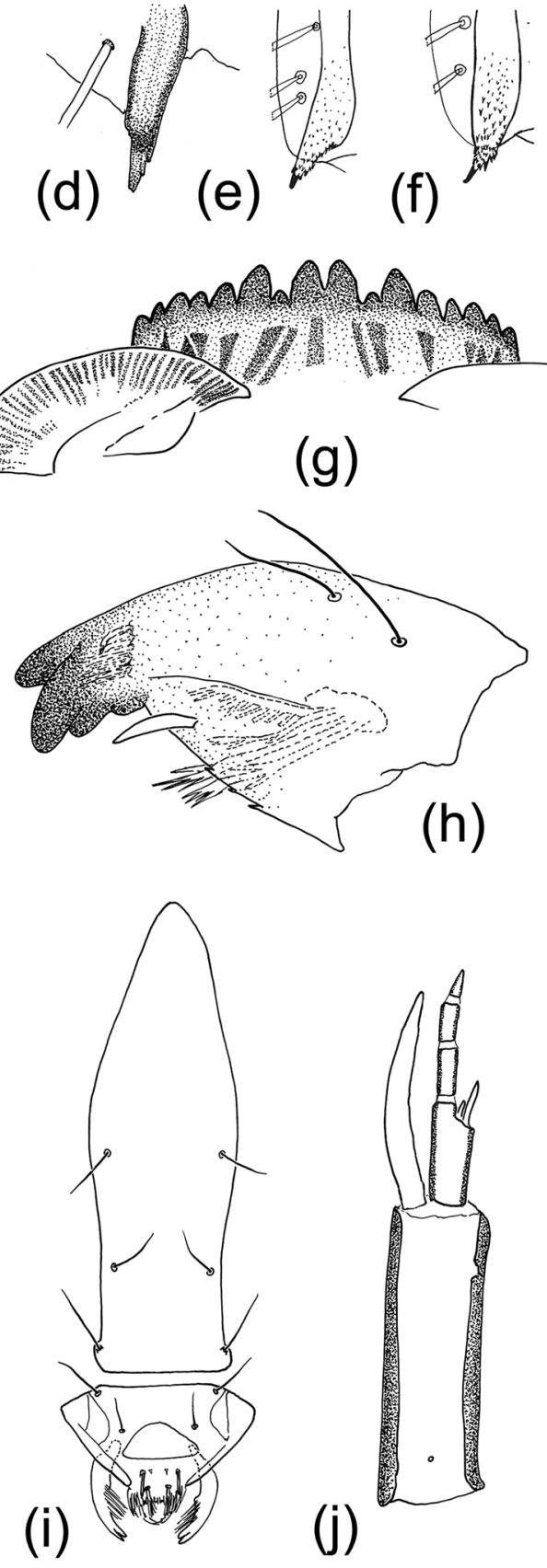

(j)

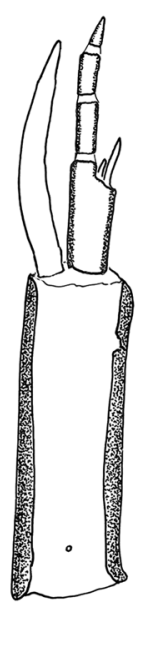

Fig. 3. Polypedilum johannseni Sublette \& Sublette. Pupa: (a, b) tergites, (c) cephalic area, (d-f) variation in caudolateral spurs. Larva: (g) mentum, (h) mandible, (i) dorsal head, (j) antenna. (a, c-d, g-j) northern Australia, (b, e-f) south China (Guangdong Prov.). 
seta 45-70 long, separated at base by $65-75$. Thorax smooth with thin line of darkened tubercles each side of midthorax. Thoracic horn hyaline, likely four branched but with all branches always entangled, non-spinose, base simple, small, circular. Abdomen (Fig. 3a,b). Tergite I without sternal or tergal armament. Hook row comprising 47-80 hooks in uniserial row (sometimes biserial laterally), extending $45-56 \%$ of width of conjunctive II. Tergites II-VI each with anterior transverse band of spines connected to medial spine areas. Tergite VII with paired anterior point patches. Tergite VIII bare. Conjunctive III bare (Fig. 3a) or with few spinules (Fig. 3b); conjunctive IV with partially aligned multiserial transverse rows of anteriorly directed spinules. Caudolateral spur of VIII (Fig. 3d-f) of three to four basally fused spines, one stronger than remainder. Pedes spurii A (vortex) on IV only, comprising whorl of pale spinules.
Pedes spurii B modestly developed on II, absent on III. Taeniate lateral setae conventional for genus - 3,3,4,4 (V-VIII). Anal lobe bare, without dorsal seta, with fringe of 24-36 taeniae, mostly uniserial but in some specimens proximally disorganised/biserial. Male genital sac extends 100-150.

Larva ( $\boldsymbol{n}=10$ ) (Figs 3g-i and $4 \boldsymbol{b}-\boldsymbol{e}$ ). Length $\sim 4-4.5 \mathrm{~mm}$, head capsule length $\sim 350-400$, pale yellow, with teeth of mentum, apex of mandible and all teeth brown-black, occipital margin narrow, pale to mid-brown, labral margin and premandible golden. Dorsal surface of head (Fig. 3i): anterior fronto-clypeal apotome only slightly broadened, with cephalic seta S3 inserted slightly subterminally. Antenna (Figs $3 \mathrm{j}$ and $4 \mathrm{c}$ ) with segments sequentially shorter than the preceding, lengths, 48-51: 15-20: 8-12: 5-10: 2.5-4, AR 1.1-1.4; Lauterborn organs barely indicated,
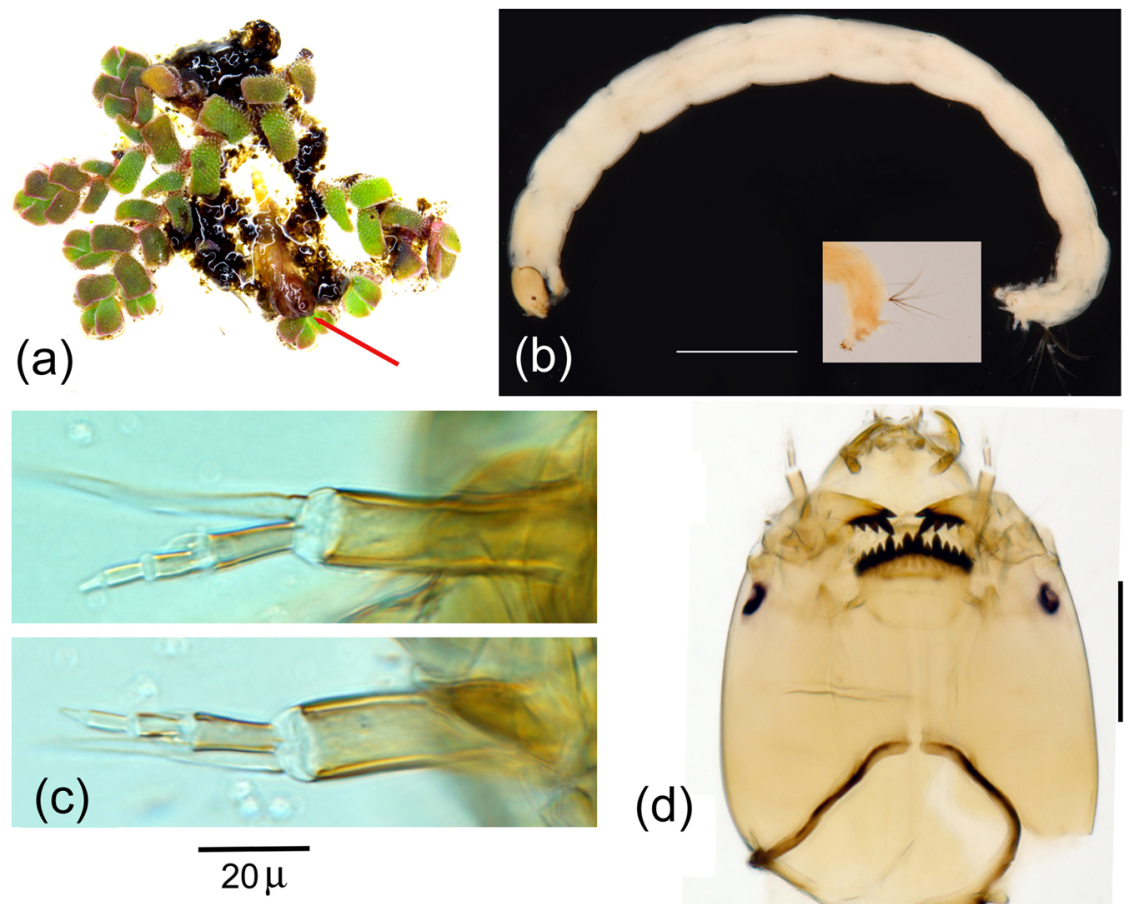

(d)
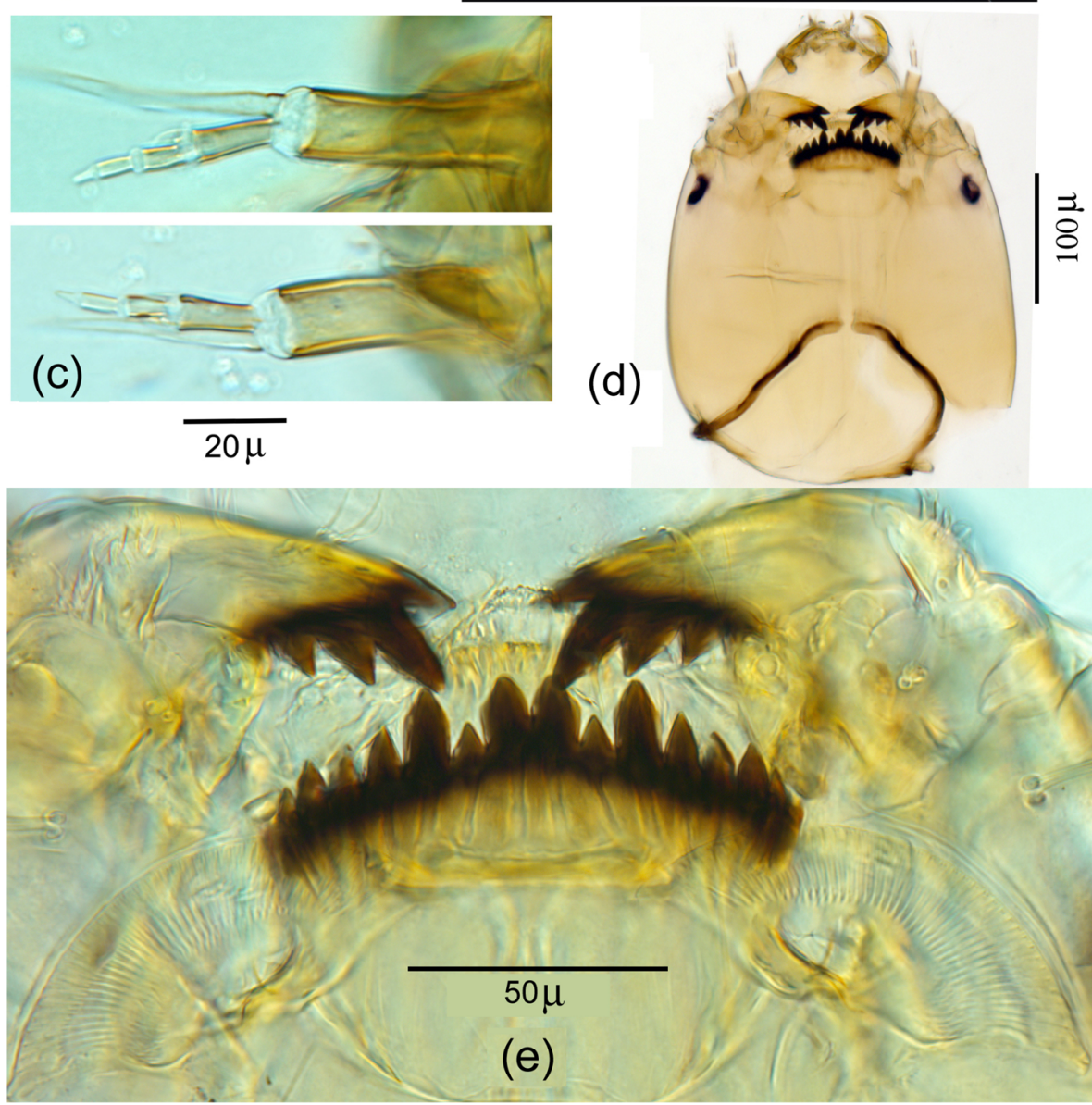

Fig. 4. Polypedilum johannseni Sublette \& Sublette. Pupa: (a) in tube in Azolla. Larva: (b) body, insert anal area; (c) antenna, two views; (d) ventral whole head; (e) mandible, mentum and ventromental plates. (a) Qld, Australia, Bradley Brown; (b-e) Singapore, Yuchen Ang. 
even at highest magnification, style slender 5-8 long; blade length 35-45, extending to apical segment but not beyond. Mandible (Figs 3h and 4e): length 120-140, with dark dorsal tooth as long as apical, two inner teeth, with small dark area on apical mola, mola with 2-3 inner spines. Labrum with finely plumose SI and SII setae pecten epipharyngis comprises three separate scales, each with three pointed teeth of unequal length; premandible 80-85, with two teeth. Mentum (Figs 3d and 4e) width 88-108, with protruding median teeth, small first laterals, second laterals tall extending to median teeth height, remainder evenly decreasing in size. Ventromental plate with $\sim 35-42$ striae, weaker on innermost $1 / 5$ of plate; plate width $75-90$, depth $30-40$, ratio $2.1-$ 2.7. Inner (median) tapered point of plate directed medially (not upcurved anteriorly). Abdomen (Fig. 4b): anterior parapod claws pale golden, simple, dense; posterior parapod claws golden. Procercus pale, apical setae pale mid-brown.

\section{Remarks}

Phytophagy. Initially, P. johannseni (as P. anticus) was described from an adult male reared from a pupa (Johannsen 1932; Lenz 1937). Although the larva was undescribed, Johannsen states that it was 'reared from larvae found on stones near shore Buitenzorg, Java' (Johannsen 1932, p. 521). An early, perhaps the first, reference to an association with aquatic plants was by Hashimoto (1985) who redescribed the male of the species, including the dimorphic female for the first time, and reported the species' association with the aquatic fern Azolla in the Philippines and Thailand. Hashimoto had not seen the immature stages or direct evidence of phytophagy but reported observations of other biologists. Subsequently, the species was reported again from Azolla in the Philippines in rice fields (Calilung \& Lit 1986) and from China (Chen 1987, recorded as Polypedilum illinoense (misspelled as 'ininoense')). Surprisingly, Hashimoto et al. (1981) had not included the species in reporting Chironominae from Thai rice fields. In Australia and Japan, new reports of larvae feeding on Azolla include direct observations of larval feeding. In Australia, feeding on A. pinnata was observed in the field in south-east Queensland and northwest Victoria and reproduced in laboratory conditions (CSIRO, Brisbane, unpublished information). In Japan, in ponds used to farm Azolla (a hybrid between A. cristata Kaulf. and non-native A. filiculoides Lam.), the fern declines rapidly due to the activities of larval P. johannseni. (N. \& M. Yamamoto, Osaka, unpublished information). In all cases, larvae constructed tubes (termed 'nests' by Japanese workers) amongst azolla fronds, comprising silk/mucus embedded with food particles and detritus including faecal material. The larva feeds around the entrance to the tube, retreating into it and often reversing direction (the tube is open at each end). Pupation takes place in the tube (Fig. 4a).

However, the species evidently is not limited to feeding on Azolla and indeed may not be an obligate phytophage on living macrophyte tissues. Larvae from a tropical billabong (horseshoe lake) in Kakadu N.P., Northern Territory of Australia, were collected live from immersed lower surfaces of Nymphoides Ség. (Menyanthaceae) and reared individually with no food supplied nor further contact with the macrophyte (P.S. Cranston, unpublished information). In China, although associated with Azolla in many waterways, $P$. johannseni larvae are found also with other aquatic macrophytes including Trapa japonica (Lythraceae), the commercial water chestnut (also in Japan, N. \& M. Yamamoto, unpublished information), ornamental Nymphaea tetragona Georgi (Nymphaeaceae) and Brasenia schreberi J.F. Gmel. (Cabombaceae), the commercial aquatic vegetables in the lower Yangtze River area. A lower frequency of larvae occurs in China on other floating-leaf aquatic plants, such as Lemna minor L. (Araceae), Pistia stratiotes L. (Araceae) and Salvinia natans (L.) All. (Salviniaceae) (H.Q. Tang unpublished information). Certainly, larval feeding can cause serious damage to Azolla, yet a diet of periphyton (aufwuchs) seems adequate to complete development. The complexity of floating Azolla plants certainly provides a massively increased surface area for periphyton development when compared to the flat surface of most other macrophytes.

The larval Polypedilum associated with Azolla are more diverse than only P. johannseni alone. In Australia, Polypedilum leei Freeman was reared with $P$. johannseni from $A$. pinnata at one location in south Queensland. In China and Japan, P. tigrinum is a frequent co-habiting species with $P$. johannseni at macrophyte-rich sites. In Japan, Polypedilum (Uresipedilum) cultellatum Goetghebuer and Polypedilum (Polypedilum) kyotoense (Tokunaga) were both found on Azolla at sites in Shiga Prefecture where P. johannseni was absent (M. \& N. Yamamoto, Osaka, unpublished observation). In China at sites without dominant Azolla, P. (Polypedilum) isigabeceum Sasa \& Suzuki and $P$. (Polypedilum) okiharaki Sasa were also frequently co-habiting with P. johannseni (H.Q. Tang, unpublished observation).

The distribution of $P$. johannseni, as currently understood, is summarised in Figure 7.

\section{Variation}

Even under our restriction of $P$. johannseni to definitive morphology, the species remains rather variable in each life stage. Geographical variation should be expected in a species with such a wide distribution extending from $35^{\circ} \mathrm{N}$ to $36^{\circ} \mathrm{S}$ and from $95^{\circ} \mathrm{E}$ to $135^{\circ} \mathrm{E}$ (Fig. 7) and from sea level to about $2000 \mathrm{~m}$ in elevation. Seasonal variation in morphometry (e.g. Kobayashi 1998) and allometry (McKie \& Cranston 2005) is to be expected. Furthermore, variation in intensity of pigmenta occurs in other strongly colour-patterned taxa such as Cricotopus (Gresens et al. 2012). Whether a taxon such as P. johannseni across such a wide range is subdivided into cryptic species associated with distribution or follows a cline within a single species can be investigated best with intensive sampling across the range and integration of morphology with DNA-based population genetics, as exemplified in recent studies of pest Tephritidae (Krosch et al. 2013, Schutze et al. 2015, Boontop et al. 2017). In descriptions and diagnoses above, we include some comments on the intensity and distribution of pigmentation and show summaries and ranges of mensural characters. Such mensural details are tabulated at population level and are made available for adult males (Table S1) and females (Table S2). Some sampling for molecular 


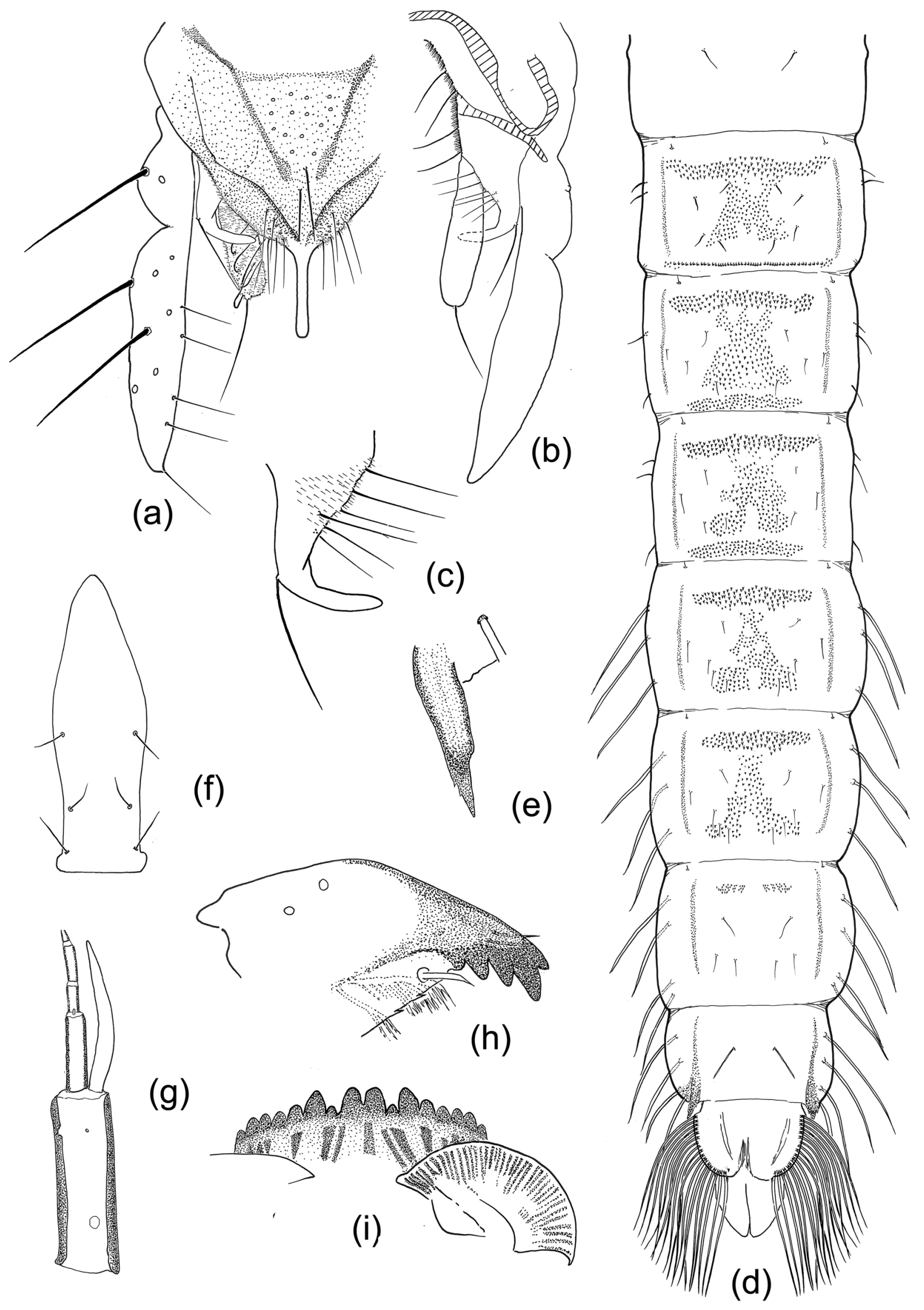

Fig. 5. Polypedilum seorsus (Skuse). Hypopygium: (a) dorsal, (b) ventral/internal, semi-stylized, (c) superior volsella. Pupa: abdomen: (d) tergites; (e) caudolateral spur of VIII. Larva: (f) frons, (g) antenna, (h) mandible, (i) mentum and ventromental plates. All NSW: Timor Rock. 
analyses has been commenced from some locations, but detailed study of the population genetic variation across the range is required to integrate partitioning of morphological variation, geography and host plant preferences in relation to species diagnostics.

\section{Chironomus seorsus Skuse, I 889}

Chironomus orarius Skuse 1889: 242, syn. Freeman 1961: 712. Polypedilum seorsus (Skuse) Freeman 1961: 712.

Polypedilum seorsus (Skuse), pro parte, Cranston 1996, 2000a (larva, pupa).

\section{Material examined}

Holotype. q, Chironomus seorsus Skuse, glued to card, Australia: NSW, Lawson (Skuse) (ANIC).

Lectotype. §, Chironomus orarius Skuse, glued to card, Australia, NSW, Middle Harbour (Skuse) (ANIC).

Other material. (all collected by Cranston, ANIC unless otherwise stated).

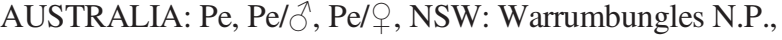
Timor Rock, Shawn's Ck., 31¹6'S 14909'E, 15.ix.1989; Le/Pe/ô, ACT, Brindabellas, Condor Ck., 35²2'S $148^{\circ} 51^{\prime} \mathrm{E}$, 6.iii.1988; §̄, SA, Belair N.P., Railway L., 13 km S.W. Adelaide, 10.i.1970, light trap (Porter \& Atchley).

Collected and determined by J. Martin, checked for distinction

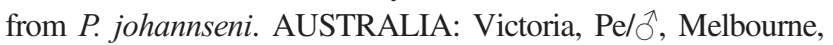

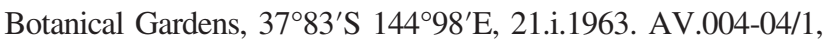
'reared from larvae from edge of lake' (NMV); L, ō, Balwyn North, 37 $79052^{\prime} \mathrm{S} 145^{\circ} 10037^{\prime} \mathrm{E}$, 9.x.2009, 'reared from egg mass \#19 from rainwater tank with about $60 \mathrm{~cm}$ water' ( $\jmath^{\lambda}$ to $\mathrm{NMV}, \mathrm{L}$ is MV in BOLD database, to ANIC).

\section{Diagnosis}

The male and female imagoes are pale overall, with bare wing membrane with veins $\mathrm{R}, \mathrm{R}_{1}$ and $\mathrm{R}_{4}+5$ setose $(\mathrm{M}$ and $\mathrm{Cu}$ veins bare), $R_{4}+5$ curved to wing apex, a non-distinctive male hypopygium (Fig. 5a-c) except perhaps for superior volsella with high number (6) of separated inner setae none of which arise from a tubercle.

The pupa has an anterior transverse band of spinules broader than median area on TII-VI, small paired patches on VII, bare VIII; conjunctives III and IV each with a transverse multiserial band of anteriorly directed spinules, bare pleurae and sternites and with dominant tooth in comb (posterolateral corner of VIII).

The larva has a five-segmented antenna with third segment $70 \%$ length of fourth, with insignificant Lauterborn organs, A. R. $\sim 1$. The mandible has the dorsal tooth shorter than the apical, with three inner teeth. The mentum has an uneven teeth pattern with outermost lateral (seventh) significantly retracted from an alignment of 3rd-6th; ventromental plate length: width ratio 2.0. (Fig. 5i).

\section{Description}

Male ( $n=1$ mature, not reared, 3 reared pharate-teneral). [Freeman (1961) in square brackets]. Body length not calculable, yellow with slightly darker lateral vittae, all legs pale yellow. Wing length $1.5 \mathrm{~mm}$ [1.8-2.0], pale, bare. Antenna plume dark; flagellomere 1-12 lengths 230-275, flagellomere 13, 270-400, AR 0.7-1.2 [1.2]. Frontal tubercles absent. Head with 3-6 verticals + postorbitals, 20 strong clypeals, palp segment lengths 2-5, $65,150,250,250$. Thorax with 0 antepronotals, 8-15 acrostichals, 1-2 humerals, 12-14 dorsocentrals, 4-6 prealars, 8-10 uniserial scutellars. Legs pale, unmarked; leg ratios: $\mathrm{LR}_{1}$ 1.7 [2], $\mathrm{BV}_{1}$ 1.48, $\mathrm{SV}_{1}$ 1.35; $\mathrm{LR}_{2}$ 0.58, $\mathrm{BV}_{2}$ 3.97, $\mathrm{SV}_{2}$ 3.03; $\mathrm{LR}_{3}$ 0.66, $\mathrm{BV}_{3} 3.28, \mathrm{SV}_{3} 2.75$; foretibial apex with triangular lobe (as in Fig. 2e), length 35, mid-leg with broad inner comb and narrower outer comb with straight spur, length 35 ; hind leg with broad inner comb, narrower outer comb with longer straight spur, length 50. Tarsi without beard. Wing pale, nonmicrotrichiose, $\mathrm{R}_{2}+3$ distinct, running at $1 / 3$ distance between $\mathrm{R}_{1}$ and $\mathrm{R}_{4+5}, \mathrm{R}_{4+5}$ long, curved, ending at wing apex, without costal extension, setation: $\mathrm{R}$ with $18, \mathrm{R}_{1}$ with $16, \mathrm{R}_{4}+5$ with 28 in distal 2/3; 5-6 squamals; V.R. 1.4. $\mathrm{M}_{1+2}$ straight.

Genitalia (Fig. 5a-c) with tergite IX bands surrounding paler oval area and fading proximal to anal point, 9-10 long median dorsal tergite IX setae; posterior margin of tergite IX with 8-9 shorter marginal setae extending to anal point base. Anal point arises from sub-posterior margin of tergite IX, evenly pigmented, near parallel sided and rounded apically. Gonocoxite conventional, bulbous; gonocoxite with basal inner margin with typical three strong setae. Gonostylus 115 long, broadest distal to base then tapering to apex, microtrichiose on both surfaces, with 5-6 inwardly directed setae on inner margin, without stronger apical seta. Superior volsella (Fig. 5c) with broad microtrichiose base, then abruptly narrowed to slender (5-6 wide) distal section, terminally rounded and slightly upcurved, 60-65 long, bearing pale fine seta, 75-85 long, originating at between 40 and $60 \%$ of length; inner margin of superior volsella with 5-6 posteromedially directed setae, not clustered or originating from tubercles. Inferior volsella microtrichiose, 57 long, with 7-8 long, and some plumose-tipped setae arise, and with distinctive strong apical seta, 65 long.

Female ( $\boldsymbol{n}=1$, pharate/teneral). Body length $\sim 2.6 \mathrm{~mm}$, teneral wing length $0.9 \mathrm{~mm}$. Yellow with slightly darker thoracic vittae and postnotum, pleura pale, abdomen yellow. Flagellomeres (14): $105,67,75,162$, antennal ratio 0.66 . Head with six linearly aligned verticals + postorbitals, 17 clypeals, palps (2-5) 52, 100,75, 138. Thorax lacking antepronotals, with nine acrostichals, one humeral, 11-14 dorsocentrals, four prealars, six scutellars. Wing pale, non-microtrichiose, $\mathrm{R}_{2}+3$ not visible /absent, $\mathrm{R}_{1}$ widely separated from $\mathrm{R}_{4+5}$, ending at $2 / 3$ wing length, $\mathrm{R}_{4}+5$, curved to end at apex of wing without costal extension; setation: $\mathrm{R}$ with $20, \mathrm{R}_{1}$ with $17, \mathrm{R}_{4}+5$ with $33 ; 6$ squamals; V.R. not calculable. Legs all teneral, unmeasured. Spurs of mid- and hind tibiae 50 long. Genitalia apparently typical for Polypedilum. Notum 125 long, seminal capsules 
subovate 70-75 wide/high, with slightly sinuous ducts, dorsomesal lobe conventional-shaped and with typical microtrichia; ventrolateral lobe small, weak, without brush-like setae; cerci $(75 \times 55)$ ovate.

Pupa $(\boldsymbol{n}=4)$. (Fig. 5d,e). Length $~ 3.6 \mathrm{~mm}$. Cephalothorax including antennal and wing sheaths pale golden, abdomen very hyaline without distinguishable apophyses and only comb darkened. Cephalothorax with frontal tubercles absent, frontal seta damaged, not visible or very hyaline. Thorax smooth with few small tubercles on eclosion line. Thoracic horn hyaline, likely four branched, base simple, small, ovoid.

Abdomen (Fig. 5d). Tergal armament: tergite I without sternal or tergal armament. Hook row comprising 60-70 hooks in uniserial row, extending $75 \%$ of width of conjunctive II, unusually with some additional non-aligned spinules at each end of row. Tergites II-VI each with anterior transverse band of spines intermittently connected to medio-posterior spinule areas. Tergite VII with paired anterior point patches. Tergite VIII bare. Conjunctives III and IV with somewhat aligned multiserial transverse rows of anteriorly directed spinules. Caudolateral spur of VIII (Fig. 5e) comprising dominant spine and few (1-3) small inner spines. Pedes spurii A (vortex) on IV only, comprising small whorl of pale spinules. Pedes spurii B absent. Taeniate lateral setae conventional for genus - 3,3,4,4 (V-VIII). Anal lobe bare, without dorsal seta, with uniserial fringe of 19-23 taeniae.

Larva $(\boldsymbol{n}=1)$. (Fig. 5f-j). Length unknown, head capsule length $\sim 350$, pale yellow, with teeth of mentum, apex of mandible and all teeth mid-brown, occipital margin mid-brown, labral margin and premandible pale golden. Dorsal surface of head with fronto-clypeal apotome broadened anteriorly, cephalic seta S3 inserted slightly posterior to broadening (Fig. 5f). Antenna (Fig. 5g) with segment lengths, 46, 17, 7, 10, 5; AR 1.1; Lauterborn organs not visible/absent, short ovoid style 3 long; blade 34 long, extending to apex of fourth segment. Mandible (Fig. 5h) 115 long, with dark dorsal tooth shorter than apical, with three inner teeth, innermost small but distinct, mola with two inner spines. Labrum with finely plumose SI and SII setae, pecten epipharyngis of three separate scales, each with three even-lengthed pointed teeth; premandible 80 long, with two teeth, brush weak. Mentum (Fig. 5j) 95 wide, with protruding median teeth, short 1st laterals, 2nd laterals extending to median teeth height, then decreasing evenly in size until the recessed and appressed outermost tooth. Ventromental plate with 24-26 striae evenly distributed across complete plate; 80 wide, 35-38 deep, ratio 2.1-2.3. Inner (median) tapered plate not upcurved. Occipital margin darkened, 6-8 wide. Abdomen unable to be described from incomplete exuviae.

\section{Remarks}

Polypedilum seorsus evidently is distinct from $P$. johannseni in all stages, as can be seen from illustrations and diagnoses and descriptions above. It is unclear why Cranston (1996) regarded them as similar other than underestimation of morphological variation, particularly in the pupal conjunctive armament, male genitalia and larval antenna, and paucity of reared material.

Freeman (1961) recognised two species described by Skuse in Chironomus as conspecific and chose the name seorsus by page priority (Skuse 1889: p. 241) rather than the male described on the following page (although the male could have been selected). Both specimens are glued to card. Fore femora and tibia of each type have been slide mounted (Cranston), but full remounting has not been undertaken due to fragility. If the question of identity is challenged in future, DNA can be extracted from the glued specimen(s), which would not be possible if slide mounted. The differentiation by Freeman in ascribing conspecificity and distinction from congeners appears valid - namely, 'small pale species with unmarked wings and legs and with simple male hypopygium; veins $\mathrm{M}$ and $\mathrm{Cu}$ bare, $\mathrm{R}_{5}$ curved, halteres pale' (Freeman 1961: 712.). Although the hypopygium is described and drawn (fig. 24d), evidently, this was not based on Skuse's male because the hypopygium of the specimen (from Middle Harbour, Sydney) is intact and immersed in dried brown glue.

Skuse's (1889) publication of the name Chironomus seorsus lacked explanation or evidence that epithet was adjectival for the purposes of nomenclature. Following the International Code of Zoological Nomenclature (ICZN 1999) Article 32.2.2, the epithet is treated as a noun in apposition [seorsus] that remains unchanged, regardless of the gender of any genus name with which it may be combined.

\section{Distribution}

Freeman (1961) reported the species only from the Sydney basin (New South Wales), including the location of the type localities of P. seorsus (Lawson) and Polypedilum orarius (Berowra and Middle Harbour). Additional specimens viewed by Freeman were from Narrabeen, Mosman and Hornsby, all in the greater Sydney area. No additional records of the species have been published, although pinned specimens without genitalia preparations from the Canberra area were added to the Australian National Insect Collection. Re-examined specimens following differentiation from $P$. johannseni show that $P$. seorsus is distributed also in western slopes of NSW (the Warrumbungles) and in upland ACT (Cranston), and South Australia and the Melbourne area (Martin) (Fig. 7). Rearings suggest that $P$. seorsus occurs in low-order streams, including those that cease to flow in Australia's evermore prevalent droughts. Although records from standing waters exist, pupal exuviae were not detected in an eastern Australian survey of lacustrine pupal exuviae (Wright \& Burgin 2007). All larval identifications without associated rearing remain questionable, as the keys in Cranston (1996, 2000a) are incomplete regarding the number of taxa estimated by pupal exuvial evidence, and use larval characters of unproven reliability.

\section{Polypedilum tigrinum (Hashimoto, 1983)}

Pentapedilum tigrinum Hashimoto, Sasa, 1988: 15.

Pentapedilum pseudotritum Ree \& Kim, 1988: 17, syn. Oyewo \& Saether, 2008: 106.

Pentapedilum utonaiprimum Sasa, 1988: 16, syn. Oyewo \& Saether, 2008: 106. 


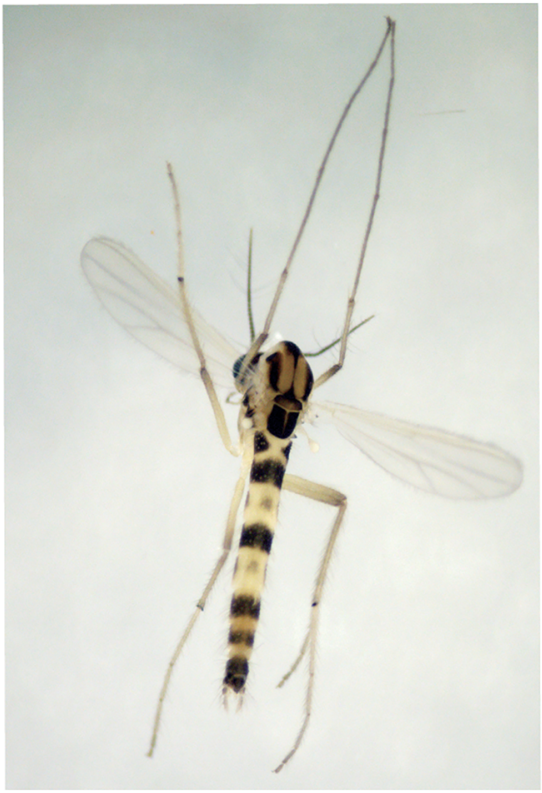

(a)

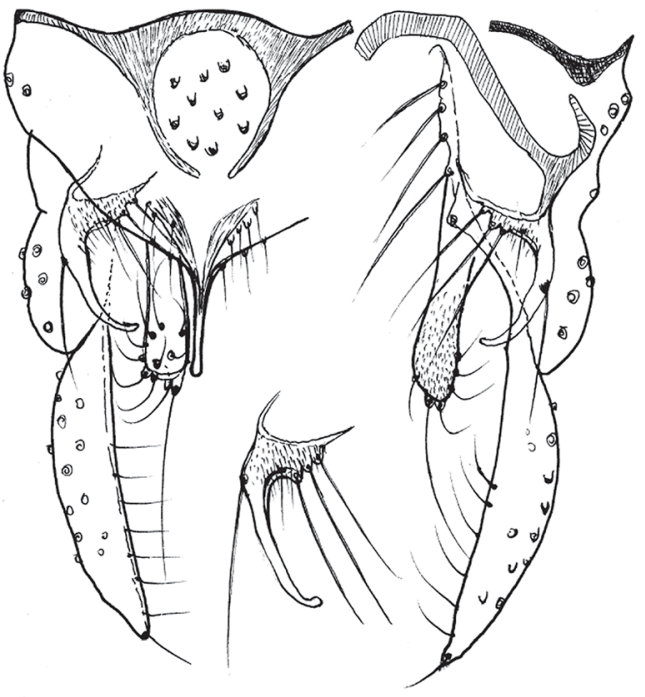

(b)

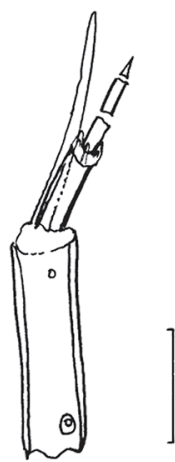

(g)

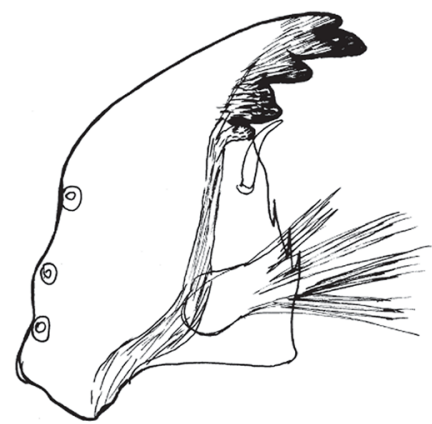

(h)

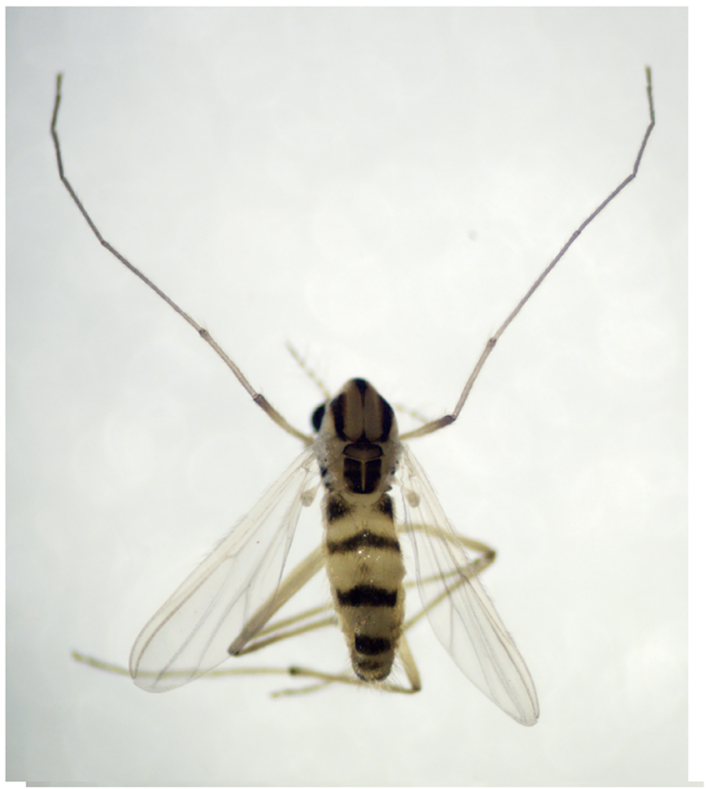

(c)

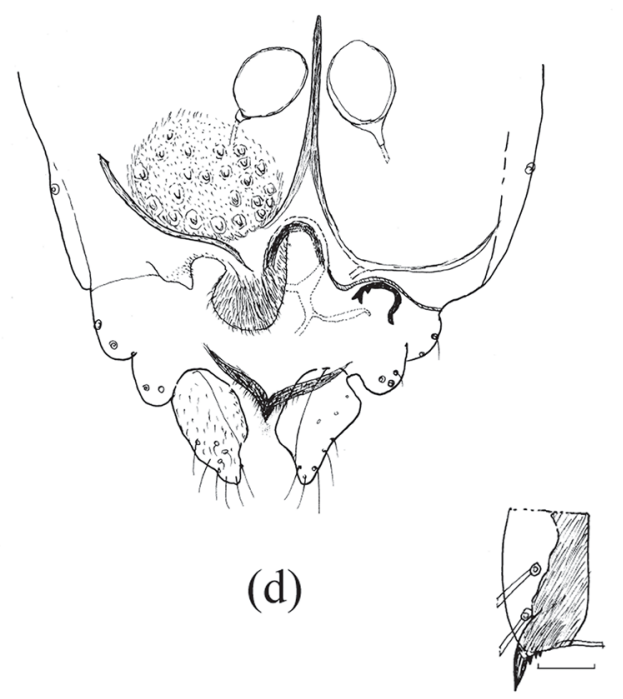

(f)
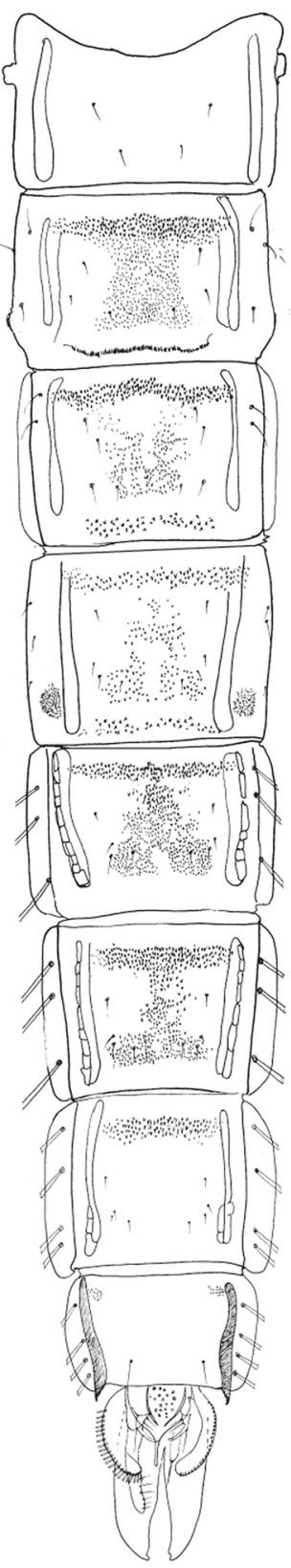

(e)

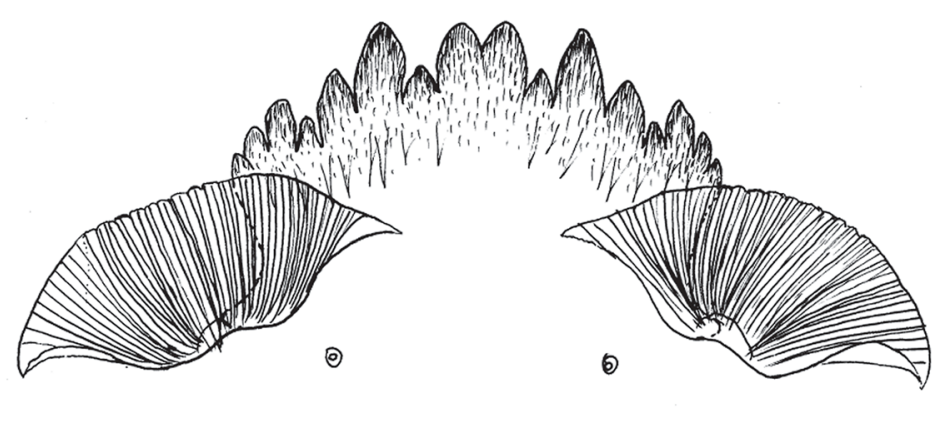

(i)

Fig. 6. Polypedilum tigrinum (Hashimoto). Male: (a) habitus (dorsal view), (b) hypopygium. Female: (c) habitus (dorsal view), (d) genitalia. Pupa: (e) abdomen, (f) caudolateral spur of VIII. Larva: (g) antenna, (h) mandible, (i) mentum. All Central China (Anhui Prov.). 
Polypedilum tigrinum (Hashimoto); Oyewo \& Saether, 2008: 106; Yamamoto et al., 2012: 39 (discussion of subgenus placement).

\section{Material examined}

(all collected by H.Q. Tang, deposited EJNU).

CHINA: North-east, $2{ }^{\top}$, Heilongjiang Prov., Mudanjiang C.,

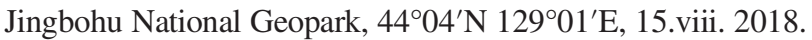

Centre, ${ }^{\lambda},+$, , Tianjin Mun., Ji Co., Yuqiao Reservoir, $40^{\circ} 01^{\prime}$ N $11^{\circ} 28^{\prime} E$, 22.x.2017; 20̄, Shandong Prov., Jining C., Centre Distr., Jinghang Canal, Huotouwan Bay, $35^{\circ} 26^{\prime} \mathrm{N} 116^{\circ} 30^{\prime} \mathrm{E}$,

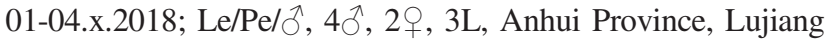
Co., Huangpi L., $31^{\circ} 10^{\prime} \mathrm{N} 117^{\circ} 23^{\prime} \mathrm{E}$, 8.v.2019.

South-east, §ิ, Zhejiang Prov., Xianju Co., Kuocangshan N. N.R., Yu country, $28^{\circ} 39^{\prime} \mathrm{N} 120^{\circ} 35^{\prime} \mathrm{E}, 05 . v .2019$. South, $2 \hat{0}^{\lambda}$, Guangdong Prov., Guangzhou C., Huadu Distr., Hongshan Country, $23^{\circ} 34^{\prime} \mathrm{N} 113^{\circ} 17^{\prime} \mathrm{E}$, 15-16.vii.2017; 3今, 2q, Tianhe Distr., Pearl Park, $23^{\circ} 07^{\prime} \mathrm{N} 113^{\circ} 20^{\prime}$ E, 13-14.ix.2018.

\section{Diagnosis}

Wing membrane with macrotrichia in apex, more setose in female. Abdomen with characteristic colour pattern, generally tergite I, II, IV, VI-VIII with full dark brown transverse bands, other segment with weak pigmentation in median or lateral (Fig. 6a,c). Male hypopygium (Fig. 6b) similar to the previous species, superior volsella with three strong inner setae arising from tubercle. Female with a broad dorsomesal lobe and nearly bare small ventrolateral lobe (Fig. 6d).

Pupa (Fig. 6e) with anterior transverse band of spinules broader than median area on TII-VI, tight connection between anterior transverse band and median patch present on TII and TVI, separated or weakly connected present in TIII-V, a single strong anterior transverse patch always present on VII; conjunctives III and IV each with a complete transverse 3-4 rows of anteriorly directed spinules, comb in posterolateral corner of VIII with dominant tooth.

Larva with uneven mentum, five-segmented antenna with third segment length subequal to fourth, small Lauterborn organs present, antennal blade longer than flagellum. A.R. more than 1.0. Mandible with two inner teeth. Mentum with uneven teeth pattern, fourth laterals significantly lower than the alignment of 3rd-7th (Fig. 6i), similar size to first laterals.

\section{Description}

Male ( $n=5$ mature, not reared, 2 pharate-teneral) [Oyewo \& Saether (2008) in square brackets]. Body length 2.9-3.5 mm, yellow with dark lateral and centre vittae; postnotum, anepisternum II, postepisternum II and anterior epimeron II dark brown; scutellum partially brown. Legs generally grey brown, anterior femora slightly dark brown; abdomen with characteristic colour patterns, generally tergite II, IV, VI-VIII with full dark brown transverse bands with others weak pigmentation in others terga (Fig. 6a). Wing length 1.5-1.7 mm [1.44-1.67], with a few macrotrichia in the apical cells $r_{4+5}$ and $m_{1+2}$. Antenna with brown flagellomeres and dark plume; flagellomere 1-12 lengths,
380-420, flagellomere 13, 520-550, AR 1.2-1.4 [1.38-1.68]. Frontal tubercles absent. Head with 10-14 temporals, 20-25 strong clypeals, palp segment lengths $2-5$, 32-40; 60-70; 75$100 ;$ 130-138. Thorax without antepronotals, with 10-14 acrostichals, 1-2 humerals, 10-13 dorsocentrals, 4-5 prealars, 6-9 scutellars. Legs: anterior half of femur pale yellow, the kneels slightly dark brown, other segments grey brown, unmarked; leg ratios: $\mathrm{LR}_{1} 1.67-1.87(n=3)$ [1.69-1.73], $\mathrm{BV}_{1}$ 1.60-1.67 [1.51], SV $1.27-1.48$ [1.38]; $\mathrm{LR}_{2}$ 0.48-0.50 [0.530.56 ], $\mathrm{BV}_{2}$ 3.73-3.82 [3.43-3.83], $\mathrm{SV}_{2} 4.35-4.38$ [3.74-4.33]; $\mathrm{LR}_{3}$ 0.60-0.67 [0.68-0.71], $\mathrm{BV}_{3}$ 2.70-2.90 [2.66-2.88], $\mathrm{SV}_{3}$ 3.17-3.20 [3.06-3.17]; foretibial apex with acute point (Fig. 2e). Wing. $R_{2+3}$ running close to $R_{1}$ and widely separated from $\mathrm{R}_{4+5}$. Wing setation: $\mathrm{R}$ with $20-24, \mathrm{R}_{1}$ with $10-13, \mathrm{R}_{4+5}$ with 18-28; $\mathrm{M}_{1+2}$ 18-20; cell setae restricted in apices, $\mathrm{r}_{4+5} 18-28$; $\mathrm{m}_{1+2}$ 12-18; 5-8 squamals; V.R. 1.19-1.24 [1.06-1.61].

Genitalia (Fig. 6b). Anal tergite IX bands surrounding paler area and fading posteriorly short of the base of anal point; at base of anal point, 8-10 long median dorsal tergite IX setae; posterior margin of tergite IX with 4-6 marginal setae and 3-4 setae around anal point base. Anal point straight, nearly parallel-sided towards apex, 50-60 long. Inferior volsella microtrichiose except for bare subapical area within which 8-12 dorso-medially orientated long setae arise. Superior volsella (Fig. 6b) arises from slightly broadened base, 65-70 long, basal section microtrichiose, bearing 3-4 long setae arising from the tubercles, lateral seta located in the basal 1/3-1/4, extending beyond the apex of superior volsella. Gonocoxite bulbous, gonostylus 120-130 long, with 5-8 mesally directed setae on inner margin, with dominant apical seta.

Female $(\boldsymbol{n}=3)$. Body length $2.4-3.0 \mathrm{~mm}$, wing length $1.3-$ $1.8 \mathrm{~mm}$. Colour similar to male (Fig. 6c). Antenna usually four segmented, flagellomeres 1-3: 110-125, flagellomere 4: 170195 , antennal ratio $0.63-0.68$; the last flagellum sometimes separated medially, giving appearance of five segments. Head with 10-12 temporals, 24-32 strongly clustered clypeals, palps (2-5) $30-40, \quad 60-70, \quad 80-100, \quad 120-140$. Thorax with 14-18 acrostichals, 1-2 humerals, 10-16 dorsocentrals, 2-3 prealars, 7-8 scutellars. Wing plain, with several setae restricted in extreme apices. Wing setation: $\mathrm{R}$ with $18-20, \mathrm{R}_{1}$ with $10-12$, $\mathrm{R}_{4}+5$ with $28-35 ; \mathrm{M}_{1}+218-38 ; \mathrm{r}_{4}+{ }_{5} 24-28 ; \mathrm{m}_{1+2} 30-36 ;$ 4-10 squamals; V.R. 1.16-1.18.

Legs: similar to the male; leg ratios: $\mathrm{LR}_{1} 1.63-1.72, \mathrm{BV}_{1}$ 1.50-1.65, SV $1.36-1.50 ; \mathrm{LR}_{2}$ 0.49-0.50, BV 2 3.56-3.77, $\mathrm{SV}_{2} \quad 4.33-4.44 ; \quad \mathrm{LR}_{3} \quad 0.63-0.68, \quad \mathrm{BV}_{3} \quad 2.78-2.96, \quad \mathrm{SV}_{3}$ 3.11-3.34

Gonapophysis with a larger dorsomesal lobe and small rodlike ventrolateral lobe, the latter with microtrichia only on the basal margin (Fig. 6d).

Pupa (n=3) (Fig. 6e,f). Length 3.1-4.2 mm, cephalothorax including antennal and wing sheaths outlined in brown, abdomen hyaline with indistinct apophyses and only comb darkened. Cephalothorax. Frontal tubercles absent, pale frontal seta 5560 long, gap between two setal pockets 62-65. Thorax smooth 
with thin line of brown granulation along the median suture. Thoracic horn hyaline, six branched, base simple, small, circular.

Abdomen (Fig. 6e). Tergal armament, tergite I without sternal or tergal armament. Hook row comprising 50-70 hooks in uniserial row (sometimes biserial laterally), extending 57-68\% of width of conjunctive II. Tergites II-VI each with anterior transverse band of spines connected to medial spine areas. Tergite VII with one complete transverse anterior band. Tergite VIII with a small pair of anterolateral patches. Conjunctive III and conjunctive IV slender, with partially aligned 3-4 rows of spinules. Caudolateral spur of VIII (Fig. 6f) of three to four basally fused spines, one stronger than remainder. Pedes spurii A (vortex) on IV only, comprising whorl of pale spinules. Pedes spurii B weakly developed on II, absent on III. Anal lobe bare, without dorsal seta, with fringe of 28-36 taeniae, mostly uniserial, anal lobe ratio 1.57-1.76, male genital sac extending 120-135.

Larva $(\boldsymbol{n}=3)$ (Fig. $6 \boldsymbol{g}-\boldsymbol{i})$. Length $3.7-4.3 \mathrm{~mm}$, head capsule length 400-440, pale yellow, with teeth of mentum, apex of mandible and all teeth brown-black, occipital margin narrow, dark brown, labral margin and premandible golden. Dorsal surface of head as generic diagnosis. Antenna (Fig. 6g) segment lengths, 45-50: 15-20: 8-10: 6-10: 2.5-5, AR 1.1-1.3; Ring organ located at basal $1 / 4-1 / 3$ of basal segment. Lauterborn organs present, style slender 4-5 long; blade length 45-50, extending beyond the apical segment, blade/flagellum 2-5 1.11-1.20. Premandible 70-85, with two teeth. Mandible (Fig. 6h): length 115-135, with dark dorsal tooth as long as apical, two inner teeth, with small darkened area on apical mola, inner margin with 2-3 spines. Mentum (Fig. 6i) width 83-113, with protruding median teeth, small first laterals, second laterals as tall as median teeth height, the fourth laterals distinctly smaller than the neighbour teeth, the last outer teeth (seventh) minute, lower position. Ventromental plate with $\sim 32-42$ striae; plate width 80 98, depth 33-35, ratio 2.5-2.8. Inner (median) tapered point of plate directed medially (not upcurved anteriorly), inter-plate distance 30-35. Gap between two seta submenti 60-63, postmentum 198-220 [147]. Abdomen. Anterior parapod claws pale golden, simple, dense; posterior parapod claws golden. Procercus pale, 20-25 high, 15-18 wide, bearing 7-8 anal setae, 450-600 long. Supra-anal seta 280-360 long. Anal tube straight, without constrictions, ca. $0.5-0.6$ length of posterior parapods.

\section{Variation}

In the male, the dark median vitta varies from broad to a single dark line, dotted by the setal pores of the acrostichals, and the extension can be restricted in the anterior half of mesothorax or run the full length of the mesothorax. In the abdomen, the fully banded tergite usually is consistent on TII, IV, VIII but shows great variation on other segments. TI usually with paired anterolateral markings but is never full banded; TIII and TV usually show weak pigmentation, slightly brown in centre median and lateral pleural or can be completely pale yellow in some teneral forms. Darkening of TVI-VII usually is restricted to the apical half, with a broad pale-yellow area in the posterior half. In the hypopygium, the number of basal setae in superior volsella varies from 2 to 4 , arising from a tubercle-like base. The outer lateral seta is located about basal $1 / 4$ but sometimes is absent on the opposite side, extending to the anal point apex. Several basal setae of the inferior volsella are branched subterminally.

In the female, the antenna could be interpreted as being four or five segmented. The last segment may be weaker in certain specimens, giving a five-segmented appearance. Colour variation is similar to that of the male.

In the pupa, the transverse band of spinules on conjunctives III and IV seems always present, with 3-4 rows of anteriordirected spinules. This conjunctival band can be incomplete, present as paired patches. The anterior transverse band of TVII is consistent in being complete, with stronger spinules in the middle section. The major comb teeth sometimes are acute triangular, not 'drop like' as in P. johannseni.

In the larva, the outermost lateral mental teeth are usually covered by the ventromental plate or reduced and difficult to observe in some specimens. Although the fourth laterals are clearly lower than the neighbours, this has low discriminative power in an aberrant mentum. The median two teeth with normal base, not dilate in the middle, subequal in the height to the second laterals.

\section{Remarks}

The abdomen colour pattern of $P$. tigrinum resembles $P$. johannseni superficially, as does the pupa, but differs in all stages as shown in illustrations, and the diagnoses and descriptions above. The species is characterised by the limited macrotrichia on the wing apex, which is a key 'diagnostic' character state for subgenus Pentapedilum. Hashimoto (1983) put much weight on the macrotrichose wing in grouping several heterogenous species, including P. tigrinum, into Pentapedilum ranked as genus. Arguing that a macrotrichiose wing may be homoplasious, not synapomorphic, Yamamoto et al. (2012) suggested $P$. tigrinum should be transferred to subgenus Polypedilum. Furthermore, according to Oyewo and Saether (2008), 'core' Pentapedilum typically has a brush-like ventrolateral lobe in the female; the median patch of spinules on tergite III-V usually is divided into several patches in the pupa, and usually, there is no connection between the anterior transverse band and the median area, and the comb spur on VIII usually projects and in the larva, the blade ends short of the flagellum. None of these character states are found in P. tigrinum, and thus, we concur with Yamamoto et al. (2012) that $P$. tigrinum is best placed into sg. Polypedilum rather than Pentapedilum.

\section{Distribution}

The species is widely distributed (Fig. 7) in eastern China through most of northern Heilongjiang Province to southern Guangdong Province. A similar pattern can be found also in Japan from Hokkaido to Honshu (Yamamoto \& Yamamoto 2014) and also in Korea (all recorded as P. pseudotritum) from northern Gangwon-do (Ree \& Jeong 2010) to western Chungchong-namdo (South Chungcheong Province) (Ree \& 


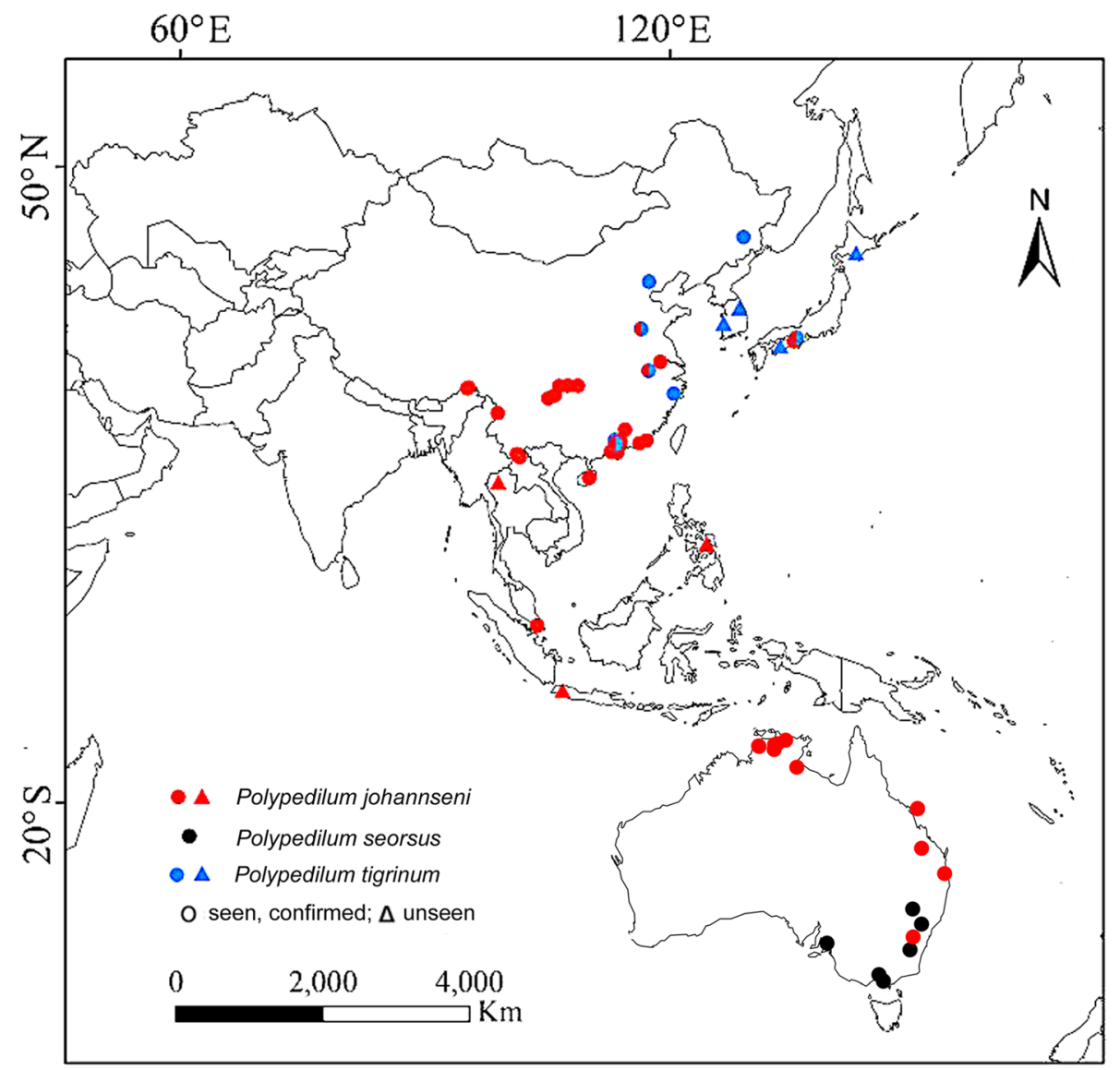

Fig. 7. Distribution. Polypedilum johannseni, red circles; Polypedilum seorsus, black circles; Polypedilum tigrinum, blue circles - specimens viewed; triangles - from literature.

Kim 1988). There are no reports outside of the above three countries.

\section{Host plants}

The larval host plant ranges from Hydrilla verticillata (L. f.) (Hydrocharitaceae), Nymphaea tetragona Goergi (Nymphaeaceae) and Trapa incisa Sieb. \& Zucc. (Lythraceae). At most collection sites, several floating-leaved plants grow and $P$. johannseni is a common co-occurring species.

\section{DISCUSSION}

Polypedilum johannseni is a distinct species in all life stages and on morphology is seen to occur from Australia through China and Japan. Within this range, the larvae can feed on (and damage) Azolla and some other macrophytes, but other records are not from these plant hosts. Molecular studies will be required to verify that $P$. johannseni is a single widespread species with variation or can be divided into segregates based either on geography or perhaps differences in use of aquatic macrophytes as a larval food.

Polypedilum seorsus is a distinct species only from Australia, where it has a temperate distribution and is not known to feed on aquatic macrophytes. Polypedilum tigrinum is a distinct Asian species with larvae feeding on a range of aquatic macrophytes including Azolla.

\section{ACKNOWLEDGEMENTS}

The Australian Biological Resources Study (ABRS) supported collecting in Australia in the 1980s and 90s, with concurrent support for survey of Alligator Rivers Region, Northern Territory, by the Office of Supervising Scientist (via Chris Humphrey). These sources provided a systematic foundation for aquatic entomological studies in remote Australia. In Singapore, collections were made under auspices of PUB-NUS project 'Chironomid Mass Emergences in Singapore: Monitoring Protocols and Identification of Triggers' (grant number R-154-000-526-490), and we thank Yuchen Ang (Lee Kong Chian Natural History Museum, Singapore) who kindly provided several images. In China, collections were partially supported by the National Natural Science Foundation of China (grant numbers 41672346 and 31100389). We are very grateful to Masaru and Nao Yamamoto (Osaka, Japan) for extensive interchange of views on Polypedilum and for allowing us to cite their unpublished information and in mailing specimens from Japan. On our behalf, Martin Spies (Zoologische Staatssammlung München (Germany)) examined Lenz' material and compared to figures we provided - we thank him for this and for commenting on identification difficulties and morphological nomenclatural 
issues. In addition, Jon Martin (Melbourne University) checked his specimens of Polypedilum seorsus against our descriptions, figures and notes on differentiation. We thank Neal Evenhuis (Hawai'i) for verifying our understanding of the nomenclature and Jinxing Wei for mapping the species distribution.

\section{REFERENCES}

Andersen T, Bello Gonzalez OC, Baars J-R \& Earle W. 2015. A new invasive weed-feeding species of Polypedilum (Pentapedilum) Kieffer from South Africa (Diptera: Chironomidae, Chironominae). Zootaxa 4000, 559-570.

Ang Y, Wong JL \& Meier R. 2013. Using seemingly unnecessary illustrations to improve the diagnostic usefulness of descriptions in taxonomy - a case study on Perochaeta orientalis (Diptera, Sepsidae). Zookeys $355,9-27$.

Armitage P, Cranston PS \& Pinder LCV, eds. 1995. The Chironomidae. The Biology and Ecology of Non-biting Midges. Chapman \& Hall, London xii +572 pp.

Balci P \& Kennedy JH. 2003. Comparison of Chironomids and other macroinvertebrates associated with Myriophyllum spicatum and Heteranthera dubia. Journal of Freshwater Ecology 18, 235-247.

Boontop Y, Kumaran N, Schutze MK, Clarke AR, Cameron SL \& Krosch MN. 2017. Population structure in Zengodacus cucurbitae (Diptera: Tephritidae) across Thailand and the Thai-Malay peninsula: natural barriers to a great disperser. Biological Journal of the Linnean Society 121, $540-555$.

Calilung VJ \& Lit IL Jnr. 1986. Studies on the insect fauna and other invertebrates associated with Azolla spp. Philippine Agriculturist 69, $513-520$.

Chen JJ. 1987. Study of the biological properties and control of azolla midge [China]. agris.fao.org/agris-search/search.do?recordID $=$ PH19900016184 [conference abstract] (viewed July 9 2019).

Cranston PS. 1995. Morphology. In: Armitage PD, Cranston PS \& Pinder LCV. (Eds.), Chironomidae: Biology and Ecology of Non-biting Midges. Chapman \& Hall, London, pp. 11-30. https://doi.org/10.1007/978-94011-0715-0_2

Cranston PS. 1996. Identification Guide to the Chironomidae of New South Wales, Vol. 1, pp. 1-376. Australian Water Technologies Pty Ltd, West Ryde, NSW. AWT Identification Guide.

Cranston PS. 2000a. 'Electronic Guide to the Chironomidae of Australia'. Pics. 1-4. http://apes.skullisland.info/sites/default/files/webfiles/members/pete/start.pdf; (accessed 13 July 2019)

Cranston PS. 2000b. Three new species of Chironomidae (Diptera) from the Australian wet tropics. Memoirs of the Queensland Museum 46, $107-127$.

Cranston P.S. (2013) The larvae of the Holarctic Chironomidae (Diptera: Chironomidae)-2. Morphological terminology and key to subfamilies. In: Chironomidae of the Holarctic Region: Keys and diagnoses. Part 1. Larvae. Insect Systematics and Evolution Supplements, Vol. 66 (eds T Andersen, PS Cranston \& JH Epler), pp. 13-24.

Cranston PS. 2018. Paraskusella Cranston, a new Afro-Australian genus in the tribe Chironomini (Diptera: Chironomidae). Austral Entomology [v. o.R. 15 October 2018] 50, 268-281. https://doi.org/10.1111/aen.12366

Cranston PS. 2019. Riethia (Kieffer 1917) (Diptera: Chironomidae) revised for the Austro-Pacific region. Zootaxa 4646 (3), 461-500.

Cranston PS, Dillon M, Pinder LC \& Reiss FR. 1989. Keys and diagnoses of the adult males of the subfamily Chironominae (Diptera, Chironomidae). Entomologica Scandinavica Supplement 34, 353-502.

Cranston PS, Martin J \& Spies M. 2016. Cryptic species in the nuisance midge Polypedilum nubifer (Skuse) (Diptera: Chironomidae) and the status of Tripedilum Kieffer. Zootaxa 4079, 429-444.

Cranston PS \& Tang H. 2018. Skusella Freeman (Diptera: Chironomidae): new species, immature stages from Africa, Asia and Australia, and expanded distributions. Zootaxa 4450, 41-65.
Earle W, Mangan R, O'Brien M \& Baars J-R. 2013. Biology of Polypedilum n. sp. (Diptera: Chironomidae), a promising candidate agent for the biological control of the aquatic weed Lagarosiphon major (Hydrocharitaceae) in Ireland. Biocontrol Science and Technology 23, 1267-1283.

Ekrem T, Ashe P, Andersen T \& Stur E. 2017. Chironomidae (non-biting midges). In: Manual of Afrotropical Diptera, Vol. 2. Nematocerous Diptera and lower Brachycera (eds AH Kirk-Spriggs \& BJ Sinclair), pp. 813-863. Suricata 5. SANBI Graphics and Editing, Pretoria.

Epler JH, Ekrem T \& Cranston PS. 2013. The larvae of Holarctic Chironominae (Diptera: Chironomidae) - keys and diagnoses. In: Chironomidae of the Holarctic Region - keys and diagnoses. Insect Systematics \& Evolution, Supplement, Vol. 66 (eds T Andersen, PS Cranston \& JH Epler), pp. 387-556. Media-Tryck, Lund, Sweden.

Freeman P. 1961. The Chironomidae of Australia. Australian Journal of Zoology, 9, 611-737. https://doi.org/10.1071/ZO9610611

Gresens SE, Stur E \& Ekrem T. 2012. Phenotypic and genetic variation within the Cricotopus sylvestris species-group (Diptera, Chironomidae), across a Nearctic-Palaearctic gradient. In: Proceedings of the 18th International Symposium on Chironomidae, Vol. 31 (eds T Ekrem, E Stur \& K Aagaard) , pp. 137-149.Fauna Norvegica

Harms N, Grodowitz M \& Kennedy J. 2011. Insect herbivores of water stargrass (Heteranthera dubia) in the US. Journal of Freshwater Ecology 26, 185-194.

Hashimoto H. 1983. Pentapedilum (Diptera, Chironomidae) from Japan with description of a new species. Kontyu 51, 17-24.

Hashimoto H. 1985. A phytophagous chironomid, Polypedilum anticum (Johannsen). Proceedings of the Japanese Society of Systematic Zoology 31, 56-61.

Hashimoto H, Wongsiri T, Wongsiri N, Tirawat C, Lewvanich A \& Yasumatsu K. 1981. Chironominae from rice fields of Thailand with description of 7 new species. Taxonomy Branch, Entomology and Zoology Division, Department of Agriculture, Bangkok, Thailand, Technical Bulletin 7, 1-47.

ICZN. 1999. International Code of Zoological Nomenclature, 4th edn, p. 306. The International Trust for Zoological Nomenclature, London.

Johannsen OA. 1932. Chironominae of the Malayan subregion of the Dutch East Indies. Archiv für Hydrobiologie, Supplement 11, 503-552 pls. LXX-LXXVI.

Karunakaran S. 1969. Studies on the Bionomics and Taxonomy of Singapore Chironomidae. PhD Thesis. Department of Zoology, University of Singapore, Singapore, iv + $404 \mathrm{pp}$.

Kawai K, Ohsugi T, Goka K \& Imabayashi H. 2012. Genetical relationships among 22 Japanese species of the genus Polypedilum. Medical Entomology and Zoology 63, 313-317.

Kawai K, Inoue E \& Imabayashi H. 1998. Seven new species of the genus Polypedilum (Diptera: Chironomidae) from Japan. Japanese Journal of Limnology 59, 367-381.

Kobayashi T. 1998. Seasonal changes in body size and male genital structures of Procladius choreus (Diptera: Chironomidae: Tanypodinae). Aquatic Insects 20, 165-172.

Krosch MN, Schutze MK, Armstrong FA et al. 2013. Piecing together an integrative taxonomic puzzle: microsatellite, wing shape and aedeagus length analyses of Bactrocera dorsalis s.l. (Diptera: Tephritidae) find no evidence of multiple lineages in a proposed contact zone along the Thai/Malay Peninsula. Systematic Entomology 38, 2-13.

Lenz F. 1937. Chironomariae aus Niederländisch Indien. Larven und Puppen. Archiv für Hydrobiologie, Supplement 15, 1-29.

Maschwitz DE \& Cook EF. 2000. Revision of the Nearctic species of the genus Polypedilum Kieffer (Diptera: Chironomidae) in the subgenera P. (Polypedilum) Kieffer and P. (Uresipedilum) Oyewo and Sæther. Bulletin of the Ohio Survey, New Series 12 (30), 135 pp.

McKie BG \& Cranston PS. 2005. Size matters: systematic and ecological implications of allometry in the responses of chironomid midge morphological ratios to experimental temperature manipulations. Canadian Journal of Zoology 83, 553-568.

Niitsuma H. 1991. Three new species of the genus Polypedilum (Diptera, Chironomidae) from Japan. Proceedings of the Japanese Society of Systematic Zoology 45, 60-67. 
Oyewo EA \& Sæther OA. 2008. Revision of Polypedilum (Pentapedilum) Kieffer and Ainuyusurika Sasa et Shirasaki (Diptera: Chironomidae). Zootaxa 1953, 1-145.

Pinder LCV. 1986. Biology of freshwater Chironomidae. Annual Review of Entomology 31, 1-23.

Ree HI \& Kim HS. 1988. Studies on Korean Chironomidae (Diptera) III. Description of two unrecorded species from Korea and three new species. Korean Journal of Systematic Zoology, special Issue 2, 13-24.

Ree HI \& Jeong KY. 2010. Fauna of non-biting midges (Diptera, Chironomidae) from Soyang River in Chuncheon-si, Gangwon-do, Korea. Korean Journal of Systematic Zoology 26 (2), 115-140.

Sæther OA. 1980. Glossary of chironomid morphology terminology (Diptera: Chironomidae). Entomologica scandinavica 14 (Supplement), 1-51.

Sæther OA. 2001. Book review. Revision of the Nearctic species of the genus Polypedilum Kieffer (Diptera: Chironomidae) in the subgenera $P$. (Polypedilum) and P. (Uresipedilum) Oyewo and Sæther. David E. Maschwitz and Edwin F. Cook. ISBN 0-86727-130-2. Bulletin of the Ohio Biological Survey, New Series Volume 12, No. 3. 2000. Journal of the North American Benthological Society 20, 156-157.

Sæther OA \& Oyewo EA. 2008. Keys, phylogenies and biogeography of Polypedilum subgenus Uresipedilum Oyewo et Sæther (Diptera, Chironomidae). Zootaxa 1806, 1-34.

Sæther OA, Andersen T, Pinho LC \& Mendes HF. 2010. The problems with Polypedilum Kieffer (Diptera: Chironomidae), with the description of Probolum subgen. n. Zootaxa 2497, 1-36.

Sasa M. 1988. Studies on the chironomid midges collected from lakes and streams in the southern region of Hokkaido, Japan. Research Report from the National Institute of Environmental Studies 121, 8-76.

Schutze MK, Mahmood K, Pavasovic A et al. 2015. One and the same: integrative taxonomic evidence that Bactrocera invadens (Diptera: Tephritidae) is the same species as the Oriental fruit fly Bactrocera dorsalis. Systematic Entomology 40, 472-486.

Skuse AA. 1889. Diptera of Australia. Part VI. The Chironomidae. Proceedings of the Linnean Society of New South Wales 4, 215-311.

Stagliano DM, Benke AC \& Anderson D. 1998. Emergence of aquatic insects from 2 habitats in a small wetland of the southeastern USA: temporal patterns of numbers and biomass. Journal of the North American Benthological Society 17, 37-53.

Stratman K, Overholt WA, Cuda JP, Netherland MD \& Wilson PC. 2013. The diversity of Chironomidae associated with Hydrilla in Florida, with special reference to Cricotopus lebetis (Diptera: Chironomidae). Florida Entomologist 96, 654-657.

Sublette JE \& Sublette MS. 1973. Family Chironomidae. In: A Catalog of the Diptera of the Oriental Region, Vol. 1 (eds MD Delfinado \& DE Hardy), pp. 389-422. University Press of Hawaii, Honolulu.

Takara L. 1981. Insect pests on Azolla pinnata at Bangken, Thailand. International Rice Research Newsletter 6, 12-13.
Tang HQ, Cranston PS, Zhao JG, Lok CW, Wong KC \& Li ZQ. 2014. The immature stages of Polypedilum (Pentapedilum) nodosum (Johannsen) and Polypedilum (Tripodura) masudai (Tokunaga) (Diptera, Chironomidae, Chironominae). Zootaxa 3893, 416-428.

Townes HK. 1945. The Nearctic species of Tendipedidae [Diptera: Tendipedidae (= Chironomidae)]. American Midland Naturalist 34, $1-206$.

Tóth M, Móra A, Kiss B, Dévai G \& Speciár A. 2012. Are macrophytedwelling Chironomidae (Diptera) largely opportunistic in selecting plant species? European Journal of Entomology 109, 247-260.

Walker F. 1848. List of the specimens of dipterous insects in the collection of the British Museum, Vol. 1, p. 299. Trustees of the British Museum, London.

Wright IA \& Burgin S. 2007. Species richness and distribution of eastern Australian lake chironomids and chaoborids. Freshwater Biology 52, 2354-2368.

Yamamoto N, Hirowatari T \& Yamamoto M. 2012. The subgenus Pentapedilum Kieffer (Diptera: Chironomidae) in the Yaeyama Islands, the Ryukyus, Japan. Zootaxa 3191, 33-40. https://biotaxa.org/Zootaxa/ article/view/zootaxa.3191.1.3.

Yamamoto M \& Yamamoto N. 2014. Family Chironomidae. In: Catalogue of the Insects of Japan, Vol. 8. Part 1. Diptera (Nematocera Brachycera Aschiza) (ed Editorial Committee of Catalogue of the Insect of Japan), pp 237-362. The Entomological Society of Japan, Touka Shobo Publisher, Fukuoka, [In Japanese].

Zhang RL, Song C, Qi X \& Wang XH. 2016. Taxonomic review on the subgenus Tripodura Townes (Diptera: Chironomidae: Polypedilum) from China with eleven new species and a supplementary world checklist. Zootaxa 4136, 1-53.

Accepted for publication 16 September 2019.

\section{SUPPORTING INFORMATION}

Additional supporting information may/can be found online in the supporting information tab for this article.

Table S1. Adult male morphometrics. Abbreviations and locations, see text.

Table S2. Adult female morphometrics. Abbreviations and locations, see text 